\title{
FOSTERING "FAMILY": HOW COMMUNICATION SUSTAINS AND FUNCTIONS IN FOSTER FAMILIES
}

A Thesis
presented to
the Faculty of the Graduate School
at the University of Missouri-Columbia
In Partial Fulfillment
of the Requirements for the Degree
Master of Arts
LESLIE NELSON
MAY 2014
Dolleen Colaner, Thesis Adviser
Dr.


The undersigned, appointed by the dean of the Graduate School, have examined the thesis entitled

FOSTERING “FAMILY”: HOW COMMUNICATION SUSTAINS AND FUNCTIONS IN FOSTER FAMILIES

presented by Leslie Rose Nelson,

a candidate for the degree of master of arts,

and hereby certify that, in their opinion, it is worthy of acceptance.

Dr. Colleen Colaner

Dr. Haley Horstman

Dr. Catherine Rymph 


\section{ACKNOWLEDGEMENTS}

I want to thank everyone who has supported, encouraged, and believed in me over the last two years. The knowledge, support, and faith shared and shown to me by others ultimately shaped my academic identity and drove me to write this thesis. Without the many valuable interactions and experiences I have had, my passion for teaching and researching foster family communication simply would not have grown as it has. For this I am forever grateful.

First, I want to sincerely thank my advisor, Dr. Colleen Colaner, for without her constant words of encouragement, endless understanding, helpful feedback, and catchy mantras, this thesis would not have been possible. When I found myself getting hung up on an idea I would remind myself to "work smarter not harder," and this helped me press on! I can only hope to be the advisor you are one day.

Second, I want to recognize my committee members, Dr. Haley Horstman and Dr. Catherine Rymph. I am appreciative for the time you dedicated and the support you offered in helping me to see this thesis through. The classes taken with you both have equipped me with precious knowledge and inspired me to continue researching communication in the foster square.

Third, I want to acknowledge my fellow graduate students in the Department of Communication. You are truly some of the most amazing people I have met in my life and this adventure would not have been possible without you all. I will forever remember the many laughs, helpful insights, and weekly gatherings in good old Switzler Hall crunching numbers for quant. I could not have asked for a more supportive and encouraging set of "comm-rades" to share in this experience with. 
Last but certainly not least, I want to thank my participants, family and friends. To the many foster parents who took the time to complete my survey - this study could not and would not have been possible without you all sharing your experiences with me; for this I thank you!

To my family — thanks for always encouraging me to pursue my dreams and being understanding of my physical absence. A special shout out to my parents, who have always been my "biggest cheerleaders." Without your influence, guidance, and endless support, I simply would not be who or where I am today. When things got tough or seemed impossible, I would remember to "stop and smell the roses," and this helped me see that light again at the end of the tunnel. Another special shout out goes to my brother, sister-in-law, nephews, and niece: you have been and always will be my inspiration.

To Mat and K.D. - thank you for your endless support and praise over the last two years. I commend you for getting me to escape when I needed it most via some of my favorite things to do with you both: eat food, listen to vinyl, and watch Breaking Bad. It was these precious moments that kept me healthy and sane throughout this journey.

This process has been one I will never forget and challenged me to think in ways I never have before. Surviving the inevitable highs and lows associated with graduate school in addition to the thesis process was equally as stimulating as it was empowering. I am positive what I have learned will continue to shape my personal and academic identity for years to come. 


\section{TABLE OF CONTENTS}

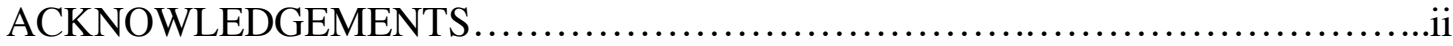

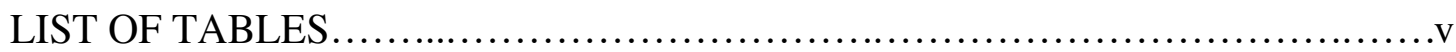

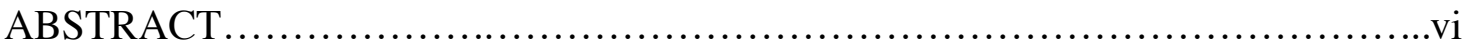

CHAPTER I: LITERATURE REVIEW ......................................

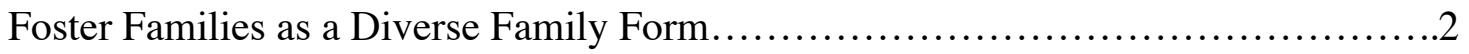

Shared Family Identity in Foster Families.....................................8

Communicative Openness in Foster Families................................12

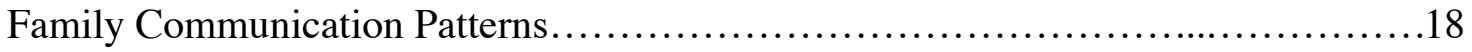

Communication Patterns, Communicative Openness, and Family Functioning.........22

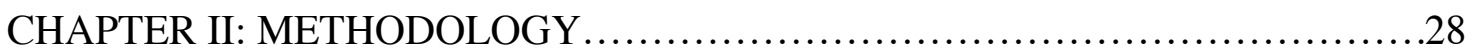

Sample and Procedure..................................................... 28

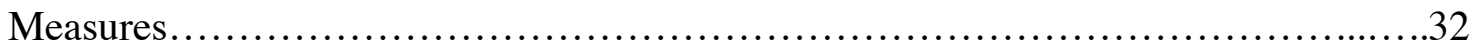

CHAPTER III: RESULTS ................................................ 35

Zero-Order Correlations.......................................................

Regression Analyses.........................................................36

CHAPTER IV: DISCUSSION ..........................................42

Summary of Findings.................................................... 42

Theoretical Contributions................................................44

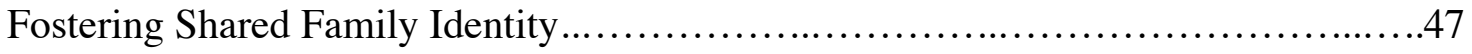

Future Research Agenda and Limitations.........................................54

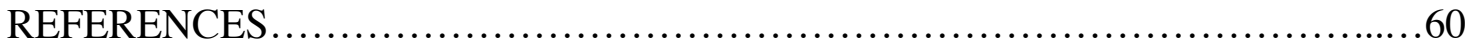

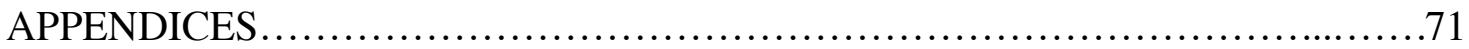

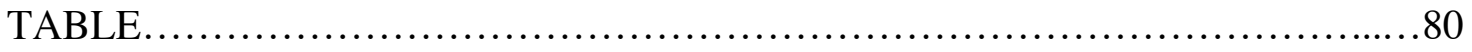




\section{LIST OF TABLES}

Table

$\underline{\text { Page }}$

i. Descriptive Statistics, Reliability Coefficients, and Correlations...............80 


\title{
FOSTERING "FAMILY": HOW COMMUNICATION SUSTAINS AND FUNCTIONS \\ IN FOSTER FAMILIES
}

\author{
Leslie Nelson \\ Dr. Colleen Colaner, Thesis Adviser
}

\begin{abstract}
While foster families are prevalent and serve a critical role in our society, little is known about the communicative dynamics connecting the foster square (e.g., foster child, foster parent(s), birth parent(s), and agency). Guided by Family Communication Patterns theory (Koerner \& Fitzpatrick, 2002), the goal of this thesis was to understand not only how foster families communicate, but also how foster parent-child communication impacts foster children as well as the parent-child relationship. Current foster parents $(\mathrm{N}=158)$ completed an anonymous online survey in which they were asked to report on their communication and relationship with a current foster child. Several significant findings emerged.
\end{abstract}

First, a positive relationship between shared family identity and both conversation orientation and relational closeness emerged. Second, communicative openness was positively associated with child's strengths and relational closeness. Third, the interactional effect of communicative openness and conformity orientation significantly predicted child strengths. Lastly, both consensual and laissez-faire parenting styles had unique effects on foster-parent child relational closeness. These findings provide valuable theoretical contributions and ultimately help to establish a foundation for future research on the foster family form. Implications for understanding how shared family identity emerges and the role of openness in the foster family form are discussed. 


\section{CHAPTER I: LITERATURE REVIEW}

The most recent Adoption and Foster Care Analysis and Reporting System (AFCARS) Report indicated there were 399,546 children in the United States foster care system in September of 2012 (AFCARS, 2013). However, to date there is a limited understanding of how communication sustains and functions in foster families. As foster families are becoming increasingly common in our society, knowledge of how foster families interact and function in, what I call, the "foster care square" (e.g. foster child, foster parent(s), biological parent(s), and foster agency) is crucial. Specifically, understanding the communication dynamics in foster families and how this relates to individual and family functioning warrants attention from family communication scholars.

Adoptive family communication provides insight into foster family communication (Brodzinsky, 2005, 2006; Galvin, 2003, 2006; Suter \& Ballard, 2009). While there is no denying foster and adoptive families face distinct challenges, they are both diverse families formed largely through language. Research on diverse family forms would suggest foster families, much like adoptive families, rely heavily on communication to create a sense of personal and familial identity (Galvin, 2003). A second way of understanding communication in foster families is to look to the existing research on how communication operates generally in families (e.g. Koerner \& Fitzpatrick, 2002, 2006; 2012). Examining foster parent's communication patterns with their foster children will allow for an assessment of the impact such communication has on individual and relational functioning as well as perceptions of shared family identity. 
Therefore, drawing from adoptive and family communication literature, the primary purpose of the present study is to gain an understanding of how foster families communicate and function as a family. Specifically, the present study seeks to explore how foster parent-child communication relates to a sense of shared family identity and individual and relational functioning. As such, the following two goals are set forth: first, to examine what predicts communication in foster families (e.g., shared family identity and communicative openness) and second, to discover how communication functions in foster families (e.g., relation to child adjustment and relational closeness between foster parent and child).

\section{Foster Families as a Diverse Family Form}

Changes in laws, customs, and practices have brought on the legitimatization of many more family forms in contemporary society (Galvin, 2003). As such, the diversity of U.S. families continues to be on the rise including adoptive, gay and lesbian, single parent, and blended families (Galvin, 2006). With this, the traditional definition of family as possessing genetic ties and having a long-term legal status is often challenged (Floyd, Mikkelson, \& Judd, 2006; Suter \& Ballard, 2009). Because of this, there is a need for more research illuminating diverse family forms - especially those that continue to challenge the traditional assumptions of family and expand our current scholarly definitions. One such family structure that fits this call and is in dire need of focused research attention is foster families.

Complex circumstances lead to children's entrance into the foster care system (AFCARS, 2013). According to Patrick (2012), poverty, substance abuse, domestic violence, and parental incarceration are the major factors contributing to children's 
entrance into the foster care system. As such, many children have experienced some form of maltreatment (e.g. neglect, violence, and/or abuse) in their biological family prior to being placed in foster care (Oswald, Heil, \& Goldbeck, 2010). Following such maltreatment, the United States child welfare, or "foster care," system steps in and finds a licensed, stable, and secure foster family for children to live with temporarily (Mekonnen, Noonan, \& Rubin, 2009).

Although foster homes provide a secure and stable environment, foster children still must adjust once placed with a foster family. The AFCARS (2013) placement data reveals a plethora of foster children placements, reporting $47 \%$ of foster children are placed with non-kin and $28 \%$ of foster children are placed with kin. Other placements included institutions (9\%), group homes (6\%), trial home visits $(6 \%)$, pre-adoptive homes (4\%), supervised independent living (1\%), and runaways (1\%). Regardless of placement type, the average amount of time children were in the foster care system was 22.7 months (AFCARS, 2013). Often foster children do not know what to expect in a foster family upon first entering the foster care system. Thus, it is worth examining this complex family structure and how foster family communication may help to sustain this diverse family type.

\section{Foster Family Communication}

Despite the large number of children in the foster care system, the complex web of relationships inherent to the foster family experience, and the innate challenges often faced by individuals in the foster care system, little is known about the communication linking the foster care square or the implications of such interactions. Although academic articles appear in journals in sociology, psychology social work, child welfare, and 
family studies, there is minimal research focusing specifically on communication in foster care or families. According to Patrick (2012), even some of the best-known texts in the field of communication focusing on family diversity (see Ferguson, 2007) do not discuss foster care or families. Galvin (2012) echoes this concern and calls for more communication-oriented studies on the foster family form.

Three plausible answers are set forth for why foster families have remained understudied thus far: (1) family scholars consider this to be a "temporary" family given the inherent definition and goals of foster care; (2) the lack of attention given to this family form in the literature to date naturally removed this family form from family scholar's considerations; and (3) researchers find this family form too difficult to access (Patrick, 2012). However, family communication researchers acknowledge exploring how communication sustains and functions in the foster family form is both important and relevant (Suter, Baxter, Thomas, and Suerer, 2014; Galvin, 2012; Patrick, 2012; Thomas, 2013). Communication has the power to help diverse families and lead to better health outcomes (Brodzinsky, 2006; Galvin, 2006; Vuchinich, Ozretich, Pratt, \& Kneedler, 2002) Therefore, examining how communication functions in foster families is imperative.

Studies from the communication discipline are just beginning to emerge. Recent research on foster care and families has empirically illuminated the importance of studying foster family communication given its impact on children's behavior. Specifically, positive parent-child communication patterns were associated with lower externalizing and internalizing behavior problems in foster children (Vuchinich et al., 2002). However, this is not to suggest there were no communicative difficulties present 
in the foster parent-child relationship. Given adolescent foster children were simultaneously coming to terms with their developmental transition and two very present families (biological and foster), communication difficulties with foster parents were often reported (Rosnati, Iafrate, \& Scabini, 2007). Foster parents took responsibility for helping children manage such transitions, although communication with the birth family proved difficult to manage at times for some foster parents (Rosnati et al., 2007). As such, knowledge of how foster parents can best communicate with their foster children as well as their birth family through these transitions to promote children's behavioral, social, psychological, and emotional outcomes is important. Therefore, a specific aim of the current study is to shed light on the impact of communication between foster parents and foster children on children's behavioral and social outcomes in particular. While research shows foster families face unique communicative challenges, it is difficult to know if the challenges stem from the structure of the family form and/or the foster child's prior negative experiences. More research is needed to explore these relationships.

A study conducted by Suter and colleagues (2014) examining online foster-toadoption narratives suggests foster parents often face communicative tensions in how they define "family." The following two discourses surfaced: the discourse of biological normativity (DBN) and the discourse of constitutive kinning (DCK) (Suter, Baxter, Seurer and Thomas, 2014). The DBN reinforces the dominant foster care and societal preference for biogenetically connected families; the DCK resists the DBN, emphasizing it is the enacted and shared behaviors and affections that constitute legitimate families, not genetics (Suter et al., 2014). Most often foster parents felt a simultaneous pull to communicate both discourses to some degree depending on the specific interaction (Suter 
et al., 2014). Foster parents experience difficulties with settling on how his/her foster child fits into one's own definition of "family." This tension reveals the natural ambiguity associated with filling a familial role temporarily.

A communication-oriented study on foster children's online narratives revealed foster children experience similar tensions when attempting to construct a stable and salient sense of self (Thomas, 2013). Three non-exclusive identities emerged from foster children's stories: victim, survivor, and victor. Children who embraced the victim or survivor identities did not appear to have enhanced general senses of well-being, nor did they discuss as many opportunities (i.e. hopeful future) when compared to victors (Thomas, 2013). However, tumultuous experiences were seen in nearly all of the online narratives. This reveals the true complexity of foster children's lives and the impact of the foster square on children's exploration and understanding of their own identity. As such, the present study hopes to further explore the implications of foster parents perceiving their foster child as "family" on individual and relational functioning in foster families.

\section{Discourse Dependency}

Despite the relatively limited attention to date in family communication research, communication does serve a vital and valuable role for the foster care square. In fact, Baxter's (2004) constitutive view of communication suggests that individuals create meaning through interactions and, therefore, relationships of any type do not exist outside of communication. As such, foster families must function on a day-to-day basis through their communication. In fact, Galvin (2006) argues that the more diverse the family, the more the family will rely on communication (e.g. become discourse-dependent). Much 
like the adoption triangle, the complex web of relationships inherent to the foster care square are created, maintained, negotiated, and at times must be terminated through communication. As such, much like adoptive families, foster families are likely highly dependent on their communication to construct and build individual and family identities (Galvin, 2006).

Considering the distressing circumstances that place children in the foster care system, it is natural for children to need and desire family interactions in order to make sense of these complex and troubling experiences. Galvin notes, "adoptive families are constructed through law and language" (2003, p. 239). Language serves to establish and reaffirm family ties in adoptive families (Docan-Morgan, 2010; Galvin, 2006). The primary end goal for the majority of children in the United States child welfare system is to reunify with parent(s) or primary guardian(s). As such, foster families are more or less "temporary" families. Such a temporal status undermines the traditional definition of a family as being "long-term" (Floyd, Mikkelson, \& Judd, 2006). In the absence of permanent legal ties, foster families are constructed primarily through language. In fact, foster parents do not even have parental rights of the children in their care, as the welfare agency holds those rights. As such, it would appear foster families rely even more heavily on their communication and dialogue when constructing and managing personal and family identity given their temporary status.

From entrance to final placement, the experience of foster care is rife with uncertainty. Although the goal is for children to reunify with parents, a variety of circumstances can affect a child's permanency plan. Communication amongst the foster square is the tool used to manage this uncertainty. In internationally adopted families, the 
ambiguity of member ties often due to the visible difference caused questions and dialogue to be raised both from those inside and outside of the family (Friedlander, 1999). In foster families, the source of ambiguity may not only come in the form of visible difference, but also individual uncertainties about one's role, relationship, and future with everyone in the foster square. In other words, the temporary status is the root of the uncertainty. Of most interest to the present study is the nature of communication in foster families and how it can help or hinder children's adjustment. It is likely that foster parents discursively negotiate aspects of fostering with their foster child, depending on age (Grotevant, Fravel, Gorall, \& Piper, 1999), and this communication is necessary for the management of the inevitable uncertainties experienced by foster parents and children in particular.

Given the large number of children entering and exiting the foster system each year, the challenges faced by the many individuals involved in the foster square, and the indisputable presence of communication in these families, it is imperative that family communication researchers give a voice to this increasingly prevalent and diverse family type. In doing so, conducting research focused on not only what predicts communication in foster families, but also the links between foster family communication and individual and relational outcome variables is of utmost importance. It is first worth exploring how this diverse family structure might communicate to establish a shared family identity.

\section{Shared Family Identity in Foster Families}

Upon first entering the foster home, it is possible children may feel like outsiders. However, families construct identities over time to create a shared identity via interactions (Manning, 2006; Soliz \& Rittenour, 2012). Shared family identity refers to 
the way family members characterize, experience, or perceive the family as a group across interactional contexts (Manning, 2006). Much like adoptive families, the inherent diversity of the foster family structure positions communication as central to the construction, negotiation, and maintenance of a shared family identity (Colaner \& Galvin, 2013; Soliz \& Rittenour, 2012). Foster children face the difficult task of balancing both their birth family and foster family when constructing their personal and familial identities. Both are important forces in shaping a child's self-concept and perception of family, but these familial memberships must be reconciled with one another.

Although less is known about foster parents, past research suggests both adolescents and children are open-minded when it comes to the idea of family and tend to have a comprehensive understanding of family (Anyan \& Pryor, 2002; Ellingsen et al., 2012). Foster children can establish a sense of "family" with foster families (Andersson, 2009; Gardner, 1996) and tend to perceive "family" in one of three ways: they see both the birth and foster family as their family, they see only the birth family as their family, or they perceive the foster family as being their only family (Andersson, 2009; Ellingsen et al., 2012; Gardner, 1996, 1998; Sinclair, Wilson, \& Gibbs, 2005).

The way the child positions the birth family in relation to their foster family was a key factor in determining children's sense of belonging in foster families (Ellingsen et al., 2012; Sinclair et al., 2005). When foster children felt their birth parents were not suitable and expressed feeling closer to the foster family, they reported feeling as if they belonged with the foster family (Sinclair et al, 2005). With this, some foster children mentioned continuing contact with their foster families throughout their lives but not their birth families (Sinclair et al, 2005). In this regard, these adolescents still felt a tie to their 
biological family, but many did not wish to return to their biological families (Ellingsen, Shemmings, \& Størksen, 2011). However, adolescent foster children who included both their birth and foster families in their representation of their family usually felt loved by both sets of parents (e.g. biological and foster). This illustrates that while foster family homes may be considered a safe haven, foster children often still have ties to their birth family (Ellingsen et al, 2012).

Much like in America, the Norwegian child welfare system places a strong emphasis on children returning to their birth families. However, they are also supportive of foster parents and children forming healthy attachments (Ellingsen et al, 2012). Foster children who are able to include both the birth family and foster family in their definition of "family" ultimately represent the goals of the foster care system both in Norway and in the United States. However, the impact of an all-inclusive definition of family on children and family outcomes has not been determined to date. Therefore, it is important to understand how foster parents achieve a shared family identity with their foster children and the implications of such identification. Manning's (2006) definition of shared family identity allows for such flexibility. In other words, difference is natural and acceptable within this shared space. Being that the perspective of current foster parents will be assessed in the current study, having a strong sense of shared family identity would equate to foster parents feeling as if they are a part of the same family as their foster child.

Gaertner and Dovidio (2000) explain in their Common Ingroup Identity Model that perceived social differences can be enriched by (re)conceptualizing a relationship in terms of a shared identity. The Common Ingroup Identity Model has guided a growing 
body of research on families by revealing that differences in a family can be transcended through perceptions of a common familial identity (Soliz \& Harwood, 2006). Coming together and building a shared relational culture are important in developing harmonious interracial/ethnic relationships (Byrd and Garwick 2006). Applied to foster families, finding a common ingroup embraces and encompasses individual differences and familial memberships, thus contributing to family and child adjustment. Achieving a more inclusive sense of "we" does not have to be at the stake of the member's original, personal identities, but rather creating a dual identity (Gaertner \& Dovidio, 2000). Consequently, in achieving a more inclusive sense of "we" in foster families, foster children do not have to part with their past identity with their birth family in order to be able to embrace a new identity with a foster family.

Establishing a sense of shared family identity will likely have positive consequences at both the individual and relational levels in foster families. Shared family identity is associated with relational satisfaction in several relational types, including mother-in-law and daughter-in-law relationships, grandparent-grandchild relationships, and stepfamilies (Banker \& Gaertner, 1998; Rittenour, 2012; Soliz \& Harwood, 2006). Banker and Gaertner (1998) found a positive relationship between the stepparent and stepchild helped to facilitate the perception of the stepfamily as "family" and aided in increasing harmony within the home. Therefore, likely more positive relations between foster parent and foster child would relate to perceptions of the foster family as one cohesive group. Relational closeness is particularly important for foster family relationships because of the temporary nature of foster care placements. If foster parents and children are able to establish healthy relations with one another given their temporary 
"family life-span," it is likely that foster parents will also promote the establishment of a shared family identity. As such, the following hypothesis is set forth:

H1: Relational closeness between foster parent and child will be positively associated with perceived shared family identity.

As Manning (2006) posited, the literature on shared family identity is "fairly thin and somewhat fragmented" and tends to ignore the concept of shared family identity (p. 46). With this, how shared family identity is communicated and formed in foster families is unclear. The current study hopes to help address this gap by examining the direct links between communicative openness and foster family communication patterns to shared family identity.

\section{Communicative Openness in Foster Families}

The significance of open communication to diverse families is no recent understanding (Kirk, 1964). However, many adoption communication researchers have extended our understanding of open communication in adoptive families over the last sixty years. One such concept, Adoptive Communicative Openness (ACO), surfaced through the work of Brodzinsky on adoptive families (2005; 2006). Communicative openness "reflects the general attitudes, beliefs, expectations, emotions, and behavioral inclinations that people have in relation to adoption" (Brodzinsky, 2005, p.149). As such, ACO refers to the degree adoptive parents are willing to engage in free-flowing dialogue about a wide array of adoption-related issues and emotions with their child. Ultimately, communicative openness allows adoptees to explore the meaning of adoption through interactions with their adoptive family (Jones \& Hackett, 2008). ACO is expected to occur on three levels: intrapersonal, intrafamilial, and interfamilial (Brodzinsky, 2005; 
Neil, 2009). The intrapersonal level reflects an individual's own exploration of adoptionrelated issues and thoughts (Brodzinsky, 2005; 2006). This includes the adopted individual as well as the adoptive and birth parent(s). The intrafamilial level reflects the exploration of adoption-related issues and thoughts within the adoptive and birth families, separately (Brodzinsky, 2005; 2006). At this tier the importance of "open, active, and emotionally attuned" communication between parent and child has long-been reiterated (Brodzinsky, 2005, p. 5; Brodzinsky \& Pinderhughes, 2002; Nickman, 1985). Lastly, the interfamilial level reflects the exploration of adoption-related issues and thoughts between adoptive and birth family members (Brodzinsky, 2005; 2006). The ideas of expression and support of adoption-related emotions are also closely tied to the concept of ACO.

Communication openness research on adoptive families provides insight into foster parent-child interactions and can rightfully be applied to the foster family form given the similarly complex web of relationships. Although "Foster Communicative Openness" or "FCO" has yet to be established as a construct, considerable parallels between adoptive and foster family functioning provide a mechanism through which interactions can be better understood (Nelson, 2014). The intrapersonal level of FCO would reflect an individual's (e.g. foster child, foster parent, birth parent. caseworker) own exploration of foster-related issues and thoughts. The intrafamilial level would reflect the exploration of foster-related issues and thoughts (i.e. reasons for placement, feelings of loss, etc.) within the foster and birth families, individually. Lastly, the interfamilial level would reflect the exploration of foster-related issues and thoughts between foster and birth family members. This level would depend on if visitations 
between the child and his/her birth parent had been determined to be in the best interest of the child.

Naturally, FCO will embrace the sharing of foster placement information and emotions within the child's level of understanding and comfort. Jones and Hackett (2008) found adoption talk had the potential to bring up sensitive matters, contentious issues, and emotionally-laden topics. Given the typically negative circumstances prompting placement into foster care (Oswald et al., 2010), equally diverse and sensitive topics are expected to surface during "foster talk."

A study examining adoptive parent's narrative accounts of the challenges of adoption talk revealed a new benefit of adoption talk: the "development of shared family values and a family identity" (Jones \& Hackett, 2008, p. 170). Results suggested engaging with children's issues such as pain, understandings of their past and future, and potentially teaching children a new set of values without completely disregarding the "old ways" can be particularly challenging. However, opening the lines of communication in the family provided an opportunity for shared family values to be discussed and a shared family identity to emerge (Jones \& Hackett, 2008). The present study answers a call from Jones \& Hackett (2008) to further explore the "props" and "tools" that facilitate communicative openness as well as the greater benefits of communicative openness in helping to secure a shared family identity and shared family values (p. 170). Supportive communication has been shown to have a strong tie to shared family identity (MorrSerewicz, 2008). However, there are no empirical studies to date linking these two constructs. Therefore, the following research question is set forth: 
RQ1: Will communicative openness be positively associated with perceived shared family identity?

In accordance with the second goal of the study, understanding the implications of foster family communication on individual and relational functioning is vital. First, the links between foster communicative openness, child adjustment and relational closeness will be examined.

\section{Communicative Openness, Child Adjustment, and Relational Functioning}

The goals of foster care are undeniably in the best interests of children, but the process of moving into the foster care system is often fraught with uncertainty and anxiety, especially for foster children (Oswald et al., 2010). From the perspectives of adolescent foster children, although placement with a foster family was in the interest of their own protection, the process was often "confusing, frightening, and dehumanizing" (Johnson, Yoken, \& Voss, 1995, p. 973). Upon first transitioning into foster families, many of these children faced significant challenges. These included physical and mental health problems (i.e. self-esteem issues, intimacy issues, higher rates of depression, etc.), developmental delays, educational difficulties, and psychological and behavioral problems (Clausen, Landsverk, Ganger, Chadwick, \& Litrownik, 1998; Freundlich \& Wright, 2003; Rutter, 2000; Shin, 2005; Simmel, Brooks, Barth, \& Hinshaw, 2001; Simms, 2000; Viadero, 2010).

It is well-documented that, upon entering the foster care system children, often have mild to critical psychological needs and, consequently, are at high risk for social, emotional, and behavioral problems (Holtan, Ronning, Handegayrd, \& Sourander, 2005; Jonson-Reid, 1998; Ryan, Herz, Hernandez, \& Marshall, 2007). Therefore, it is important 
to examine the role of communication in promoting healthy relationships between foster children and parents. It is possible healthy communication could help to lessen or completely eradicate some or all social, emotional, and behavioral issues experienced by many foster children.

According to McWey, Acock, and Porter (2010), youth in foster care are up to ten times more likely to use mental health services than youth not in foster care. More specifically, Shin (2005) found that children in foster care had significantly higher rates of depression when compared to youth in the general population. However, establishing healthy relationships with foster parents and guardians has been shown to lessen the detrimental effects to children's adjustment and well-being (Ackerman \& Dozier, 2005; Legault, Anawati, \& Flynn, 2006). In fact, foster family investment, support and attachment have been shown to promote self-esteem in foster children (Denuweleara \& Bracke, 2007; Legault, Anawati, \& Flynn, 2006; Luke \& Coyne, 2008). However, lower general senses of well-being of children in foster care still warrant greater attention from communication scholars and clinicians alike. Of most interest to the present study is how communication between foster parent and child relates to child's adjustment and relational closeness.

Prior research on child adjustment has looked to behavioral indicators to assess child health outcomes (Goodman, 1997). Among the various approaches, examining a child's difficulties as exhibited by externalizing behavioral problems gives insight into a child's appropriate developmental functioning. Likewise, examining a child's strengths, present even among difficult circumstances, demonstrates the child's resiliency and thus 
indicates child well-being. Together, child difficulties and strengths give an indication of a child's adjustment (Minnis, Everett, Pelosi, Dunn, \& Knapp, 2006).

It has been that found higher levels of communication openness in adoptive families (as perceived by the child) were associated with fewer behavior problems in children (Achenbach, 1991). Likewise, Brodzinsky (2006) found children who experienced more adoptive communication openness had parents who perceived the child has having fewer behavioral issues and higher self-esteem. As such, higher degrees of foster communicative openness in foster families may be positively related to better behavioral tendencies, such as more perceived strengths and fewer perceived difficulties in foster children.

The association between FCO and relational well-being has yet to be examined. However, the adoptive communication literature does provide further insight. Kohler, Grotevant, and McRoy (2002) found that adolescents who perceived more communicative openness within their adoptive families also reported better overall family functioning. Sobol, Delaney, and Earn (1994) also found a positive correlation between open adoptive communication and feeling closer to adoptive parents. In the same regard, but pertaining to foster families, it is likely foster communicative openness, depending on the child's desired level of FCO, will be positively related to relational closeness between foster parent and child. The following is predicted:

$\mathrm{H} 2$ : Communicative openness is positively related to a) child strengths, b) child difficulties, and c) relational closeness between foster parent and child.

Next, an examination of what is known about family communication in general and its links to both relational and individual outcome variables will be considered. 


\section{Family Communication Patterns}

Families have predictable ways of communicating with each other and family communication is categorized by visible patterns. As such, family member's beliefs about communication and the communicative behaviors family members perform are closely related (Koerner \& Fitzpatrick, 2002). Two well-known constructs associated with the Revised Family Communication Patterns theory are conversation and conformity orientation. The dimensions of conversation and conformity orientations are central to the familial experience, influence how the family operates, and shape the family's shared reality (Koerner \& Fitzpatrick, 2012). As Koerner and Fitzpatrick (2002) posit, scholars have recognized the influence of both of these constructs for years, although maybe not studied under the same names. The dimensions of conformity and conversation orientation play a vital role in family functioning and are the basis for a typology used to assess various behavioral and psychosocial outcomes in families (Koerner \& Fitzpatrick, 2002; Schrodt, Ledbetter, Jernberg, Larson, Brown, \& Glonek, 2009).

Moreover, FCP is also compatible with a transactional and inherently diverse definition of family. Family relationship schemas exist in an individual's cognition and do not require any specific assemblage of family members to constitute a family (Koerner \& Fitzpatrick, 2002). It is believed every interaction contributes to how a family constructs and achieves its shared reality via the development of preferences and habits (Koerner \& Fitzpatrick, 2012). Consequently, FCP seems especially suitable for studying the communicative dynamics within the foster family form.

\section{Conversation Orientation}

According to Koerner and Fitzpatrick (2002), conversation orientation is defined 
as the "degree to which families create a climate in which all family members are encouraged to participate in unrestrained interaction about a wide array of topics" (p. 85). Families can range on this dimension from low to high. Individuals in families with high conversation orientation tend to believe "open and frequent communication is essential to an enjoyable and rewarding life" (Koerner \& Fitzpatrick, 2002, p. 85). Families high in conversation orientation are warm, supportive, and open (Koerner \& Fitzpatrick 2002; 2006; 2012). Spontaneous, frequent, and free-flowing interactions are both encouraged and valued by all members of the family. In addition to "family" topics, family member's individual thoughts, feelings, and activities are also discussed (Koerner \& Fitzpatrick, 2002). As such, family plans and decisions are often deliberated as a family and are not confined to the parent-level.

Individuals in families with low conversation orientation tend to believe that “open and frequent exchanges of ideas, opinions, and values are not necessary for the functions of the family in general or for children's socialization and education in particular" (p. 85). Individuals in these families discuss fewer topics, interact less frequently with each other, and have fewer private exchanges about thoughts, activities, and feelings (Koerner \& Fitzpatrick, 2002; 2006). As such, whole-family decisionmaking and planning are rare occasions and the parent almost always makes decisions.

\section{Conformity Orientation}

Conformity orientation refers to the "degree to which family communication stresses a climate of homogeneity of attitudes, values, and beliefs" (Koerner \& Fitzpatrick, 2002, p. 85). Families can range on the dimension from low to high. Families high in conformity orientation are cohesive, obedient, hierarchical, and traditional (see 
Koerner \& Fitzpatrick, 2002; 2006; 2012). These families tend to be conflict-avoidant and interdependent. Communication reflects obedience from children to parents and adults and parents are the decision-makers in such families (Koerner \& Fitzpatrick, 2006). As such, whole-family decision-making is a rare.

Families low in conformity orientation tend not to believe in the "traditional family structure," where communication reflects obedience from children to parents and adults (Koerner \& Fitzpatrick, 2002). Rather, these families encourage personal growth and value personal space. They tend to believe in the independence of family members, often subordinate family interests to personal interests, and will regularly include all members in family decision-making and planning (Koerner \& Fitzpatrick, 2002, 2006). An exploration of the direct link between family communication behaviors on shared family identity, relational closeness, child strengths, and child difficulties is warranted.

\section{Conversation Orientation, Conformity Orientation, and Shared Family Identity}

A case study by Manning (2006) found shared family identity was created through multi-directional communication. This was a step beyond bi-directional communication (e.g. influence from child to parents and parents to child); it was communication among and between parents and children at various moments of interaction that served to establish a shared family identity (Manning, 2006). As such, the shared family identity was co-constructed and both emphasized similarities and allowed for differences (Manning, 2006). This study demonstrated how shared family identity is both "a process and a product" (Manning, 2006, p. 63). Creating a shared family identity involved all members of the family. The roles family member's played and each member's voice ultimately served to “create, support, and challenge the themes put forth 
by the family" (Manning, 2006,p. 63). Therefore, it is through the process of family communication the product of shared family identity comes to be. Therefore, the following is predicted:

H3: Conversation orientation is positively associated with perceived shared family identity.

As for the dimension of conformity orientation and its relation to shared family identity, much less is known. In a recent study, the association between conformity orientation and shared family identity was tested but no significance was found (Beck \& Ledbetter, 2013). However, testing this relationship again with a different population is valuable for testing the validity of the proposed lack of association between these two variables. Foster families are suitable given the intrinsic diversity of the family structure and heavy reliance on communicative acts. Therefore, the following research question is set forth:

RQ2: Is conformity orientation associated with perceived shared family identity?

Not only is it important to look at these variables individually, but also how these variables may interact and work together to sustain diverse families.

\section{Communication Patterns, Communicative Openness, and Family Functioning}

Brodzinsky (2005) asserted that "what is primary for healthy psychological adjustment is the creation of an open, honest, non-defensive, and emotionally attuned family dialogue not only about adoption [or foster] related issues but in fact any issue that impacts the child's and family's life" (p.151). Communicative openness involves flexibility in communication. Both foster parents and children must be able to balance and reconcile varying dialogical tensions in their communication. Such tensions include 
openness/closeness and integration/separation, both originally theorized as part of Relational Dialectics theory (Baxter, 2004; Skinner-Drawz, Wrobel, Grotevant, \& Van Korff, 2011).

The tension of openness/closedness in foster family relationships is best understood through disclosures at both the child and parent levels. It is likely foster parents and children will have reservations about when and how much to disclose at varying times throughout the course of their relationship. For foster children, this might include knowledge of one's past or the emotional experience of the recent loss of their birth family. For foster parents, this might include his/her knowledge of the status of birth parent's rights and current actions.

The tension of integration/separation in foster family relationships is best understood through elicited emotions and communication, again, at the parent and child levels. It is likely foster parents and children will experience this tension in regard to perceptions of family identity and address terms utilized in particular. Foster parents and children are especially prone to experiencing varying levels of comfort with levels of inclusion/separateness communicated given past experiences and interactions.

Neil (2007) described five key elements of communicative openness: communication about adoption related issues with the adopted child, empathy for the adopted child, comfort with and promotion of dual connection (e.g. connection to both adoptive and birth families), communication with the birth family and, lastly, empathy for the birth family. Naturally, foster families who exhibit more openness about foster related information and emotions may simultaneously encourage a more free-flowing dialogue between parent and child within the family. 
As such, the concepts of communicative openness in foster families and conversation orientation in foster families likely relate to and interact with one another. Foster parent's high in conversation encourage questions and communication from the child and allow the child to think freely and independently. Such communication suggests, "we can talk all day about this family AND you can develop and refine your own thinking along the way." Therefore, if foster parents are more open and willing to talk not only about foster-related issues, but a variety of everyday topics (e.g. high in conversation orientation), it is likely foster parents and children will feel closer. Additionally, as previous research has shown, this likely has positive effects on not only relational closeness, but also child adjustment (Achenbach, 1991; Berry, 1991; Brodzinsky, 2006; Kohler et al; Sobol et al., 1994).

In contrast, foster parents who may be open with regard to foster-related issues, but may not be as much when it comes to everyday topics (e.g. low in conversation orientation), individual and relational outcomes may significantly differ. It is possible foster parents and/or children may feel a tension of sorts and may ask themselves: "How close are we if we only openly discuss my (child's) experience in foster care?" It is likely foster parents and children feel less close if foster parents are not willing to create a more open dialogue about a wide variety of topics. In turn, children's individual outcomes may not be significantly impacted given the lack of topics discussed openly with the child. Therefore, the following is predicted:

H4: Communicative openness and conversation orientation interact to predict a) child strengths, b) child difficulties, and c) relational closeness between foster parent and child. 
Much less is known about the interaction between communicative openness and conformity orientation in relation to foster child adjustment and relational closeness between parent and child. However, it is possible to speculate about the impact of varying levels of conformity orientation on the relationship between foster communicative openness and child strengths, difficulties, and relational closeness between foster parent and child. Foster parents high in conformity orientation emphasize cohesiveness, hierarchy, and obedience from parent to child. Such communication likely suggests, “(foster) parents know best!" Therefore, if foster parents are more willing to openly discuss foster-related issues, yet appear to impose their own viewpoints and make decisions on behalf of the foster child (e.g. high in conformity orientation), it is possible the foster child may feel a loss of agency and power when it comes to his/her foster care experience.

In contrast, foster parents who may be open to discussing foster-related issues yet value personal growth, space, and opinions (e.g. low in conformity orientation), may also promote and experience better outcomes with their foster child. It is likely this communication is indicative of parents respect for and value of the child's opinion, which may ultimately lead to better perceived individual and relational outcomes overall. However, due to the lack of empirical evidence to support the aforementioned speculations about the associations between these variables, the following research question is presented:

RQ3: Do communicative openness and a conformity orientation interact to predict a) child strengths, b) child difficulties, and c) relational closeness between foster parent and child? 


\section{Family Typologies and Foster Family Functioning}

Research shows the dimensions of conversation and conformity orientation are often dependent on one another and thus interact with one another to create four family types (Koerner \& Fitzpatrick, 2012; Rueter \& Koerner, 2008; Schrodt et al., 2008). In particular, the impact of conformity orientation has been shown to be especially sensitive to the degree of conversation orientation (Rueter \& Koerner, 2008; Schrodt et al., 2009). The four family types are consensual, pluralistic, protective, and laissez-faire.

Consensual families are high in conversation orientation and conformity orientation. Parents are interested in what children have to say, but also feel it is necessary to make decisions for both the family and child (Koerner \& Fitzpatrick, 2006). As such, parents often experience a tension: preservation of the hierarchy within the family and the encouragement of open communication and exploration of ideas (Koerner \& Fitzpatrick, 2002). Overall, research shows these families are well adjusted under the dual influence of support and firm guidance (Koerner \& Fitzpatrick, 2012).

Pluralistic families are high in conversation orientation and low in conformity orientation. Open discussions involving all family members are common occurrence in this family type. Parents are willing to accept children's opinions and let them participate in decision-making; children's autonomy and input is valued (Koerner \& Fitzpatrick, $2002 ;$ 2012). This can be associated with poor adjustment for children and is characteristic of a "permissive" parenting style (Koerner \& Fitzpatrick, 2012).

Protective families are low in conversation orientation and high in conformity orientation. The emphasis on children's obedience to parental authority coupled with the idea parents should be the exclusive decision-makers in the family ring true (Koerner \& 
Fitzpatrick, 2006). There is often little concern for open communication and justifications for choices made my parents are deemed unnecessary (Koerner \& Fitzpatrick, 2002). Children from this family type can have more difficulty adjusting than consensual families overall (Koerner \& Fitzpatrick, 2012).

Lastly, laissez-faire families are low in conversation orientation and low in conformity orientation. These families have few interactions, lack in tending to emotions, avoid conflict, and offer little to no warmth or guidance. These children are often poorly adjusted, as these families are often considered "neglectful" (Koerner \& Fitzpatrick, 2012). Worth examining is the association between these family types to both foster child adjustment and relational closeness between foster parent and child.

Once again, turning to the adoptive communication literature is essential. Rueter \& Koerner (2008) conducted a study on the effect of FCP on adopted adolescent adjustment and found that adopted adolescents were at greater risk for adjustment problems than non-adopted adolescents in protective and laissez faire families. It was also found that adolescents in families that emphasized conversation orientation (regardless of adoption status) were at lower risk for adjustment problems (Rueter \& Koerner, 2008). As such, child adjustment and relational closeness is highest for consensual and protective adoptive families in comparison to pluralistic and laissez-faire families. It is likely much the same can be expected in foster families. With this, the final hypothesis is set forth:

H5: Conformity and conversation orientations interact to predict a) child strengths, b) child difficulties, and c) relational closeness between foster parent and child. 


\section{Conclusion}

In order to understand the current context of foster family research, this chapter first provided an over of the literature on foster families as a diverse family form. This was followed by a discussion of foster family communication and shared family identity.

Finally, this chapter reviewed communicative openness in foster families, conformity and conversation orientations, and family typologies associated with individual and relational outcome variables. Broadly, the goal of this thesis is to understand how foster families communicate and function as a family Specifically, the present study seeks to explore how foster parent-child communication relates to a sense of shared family identity and individual and relational functioning. Therefore, the goals of the current study are as follows: 1) to examine what predicts communication in foster families (e.g., shared family identity and communicative openness) and 2) to discover how communication functions in foster families (e.g., relation to child adjustment and relational closeness between foster parent and child). Five hypotheses and three research questions were set forth in order to assess the relationships and interactions between key constructs. A discussion of the sample, procedure, and how constructs were operationalized is provided in the next chapter. 


\section{CHAPTER II: METHODOLOGY}

\section{Sample and Procedure}

The current sample consisted of 158 foster parents. In order to participate in this study, individuals needed to be a) 18 years of age or older and b) a current foster parent. A power analysis for a point biserial correlation was conducted in G-POWER using an alpha of 0.05 , a power of 0.80 , a medium effect size $(d=0.3)$, and two tails. Results of the power analysis revealed 134 participants would be needed to achieve adequate power for all statistical analyses. Thus, obtaining 158 survey responses was more than sufficient to run both zero-order correlation and regression analyses.

This study utilized a plethora of recruiting techniques to achieve the desired sample size. First, foster parents were recruited via open and closed foster care blogs, forums, and chat rooms online. Site leaders and/or administrators were contacted for permission to post the recruitment script (see Appendix A). Upon receiving permission, the recruitment script was posted to all approved pages.

Second, foster parents were recruited via social networking sites (Twitter and Facebook). On Twitter, relevant hash tags within pre-constructed 140-character tweets were utilized to target foster parents (i.e. "Are you a foster parent? Would you mind completing an anonymous online survey for my thesis? Thanks! \#fostercare"). On Facebook, upon joining groups associated with the foster square and child welfare, the recruitment script was shared on the group's pages via a post made by either a) the group administrator or b) the primary researcher with the permission of the group administrator. Some Facebook groups were open for all registered Facebook users to post. In these cases the recruitment script was posted freely on the group's Facebook webpage, as 
permission was not required.

Third, the snowball convenience sampling technique was utilized. Individuals within the researcher's social network were asked to share the recruitment script with any foster parent connections within his/her social networks and/or organizations associated with foster parenting.

Fourth, local, regional, and national foster care and child welfare groups, agencies, and organizations were sought out and asked to share the recruitment script containing the link to the survey with eligible foster parents. Known foster care groups, agencies, and organizations known to have directly cooperated in the recruitment of foster parents operated at the local, regional, and national levels.

Once foster parents visited the link to the survey, they were asked to read through the consent form (see Appendix B) to ensure they qualified for and agreed to the terms of participating in the study. Those who agreed were instructed to respond to survey questions as truthfully as possible. Participants were assured their responses would be anonymous and any identifying information would be removed. With this, all 158 foster parents were asked to provide general demographic data about themselves as well as their foster child.

Foster children's reported ages ranged from under one year to 18 years old with a mean age of eight years $(S D=4.9)$ while foster parent's ages ranged from 22-61 years old with a mean age of 41 years $(S D=8.3)$. There were significantly more female $(n=$ $145,98 \%)$ than male $(n=8,2 \%)$ foster parents in the current sample, and data was coded such that $1=$ males and $0=$ females. However, there was a more evenly distributed sample of female $(n=74,46.8 \%)$ and male $(n=83,52.5 \%)$ foster children reported on in 
the current study. In total, foster parents reported caring for between one and $20+$ children in total with a mean of eight children cared for in their time serving as a licensed foster parent $(S D=7.1)$.

Additional demographical variables on which the sample varied included race, education, income, relational status and length of time served as a foster parent. Caucasian foster parents accounted for $81 \%(n=141)$ of the current sample. The remainder of the sample identified as Native American $(n=7,4.4 \%)$, Hispanic/Latino ( $n$ $=4,2.5 \%)$, Asian American $(n=2,1.3 \%)$, Black/African-American $(n=2,1.3 \%)$ and "Other " $(n=1, .6 \%)$. With regard to child's race, Caucasian foster children accounted for $65.2 \%(n=103)$ of the current sample. The remainder of children in the sample was identified as Black/African American $(n=30,19 \%)$, Hispanic/Latino $(n=23,14.6 \%)$, Native American $(n=12,7.6 \%)$, “Other" including Australian Aboriginal and Biracial ( $n$ $=7,4.4 \%)$, and Asian American $(n=5,3.2 \%)$.

Being that a convenience sample was used to gather data in the current study, the distribution of reported income and educational attainment in the current sample did differ significantly from the most recent demographical understanding of the national foster parent population. The most recent report on annual foster parent income in the United States was distributed as follows: less than 15,000 (15.9\%); 15,000 - 19,999 (15.6\%); 20,000 - 24,999 (14.2\%); 25,000 - 29,999 (10.3\%); 30,000 - 34,999 (7.7\%); 35,000 - 39,999 (10.7\%); 40,000 - 49,000 (5.7\%); greater than 50,000 (19.9\%) (Rhodes, Orme, \& Buehler, in press). In contrast, reported household income in the current sample varied from under $\$ 20,000$ to over $\$ 100,000$. However, the mode household income was the "over $\$ 100,000$ " category $(21.5 \%)$. The remainder of the sample fell within one of the 
following family income brackets: under $\$ 20,000$ (1.3\%), $\$ 21-30,000$ (5.7\%), $\$ 31-$ $40,000(9.5 \%), \$ 41-50,000(10.8 \%), \$ 51-60,000(12.0 \%), \$ 61-70,000(9.5 \%), \$ 71-$ $80,000(9.5 \%), \$ 81-90,000(6.3 \%), \$ 91-100,000(7.6 \%)$.

With regard to highest educational attainment, just under one third of the current sample listed "completed college" (32.3\%) as his/her highest level of educational attainment. $24.1 \%$ of the sample had completed graduate school while $10.8 \%$ had completed some graduate school. Additionally, 25.9\% listed some college as the highest level obtained, $3.2 \%$ listed high school, and .6\% listed some high school. However, the most recent report on foster parent's highest educational attainment in the Unites States did differ significantly from the current sample. The most recent report on foster mother's highest educational attainment in the United States was distributed as follows: less than high school (17.4\%), high school/GED (21.4\%), some college (43\%), and 4-year college degree or more (18.2\%) (Rhodes, Orme, \& Buehler, in press). Second, foster father's highest educational attainment in the Unites States was distributed as follows: less than high school (14.4\%), high school/GED (27.2\%), some college (38.6\%), and 4-year college or more (19.8\%) (Rhodes, Orme, \& Buehler, in press). It is likely the convenience sample skewed these demographical variables in the current sample. As such, results should be interpreted with these differences and the current sample in mind.

Lastly, in response to being asked their current relational status, the majority of the sample was married (76.6\%). The remainder of the sample reported the following for their relational status: $7 \%$ never married, $5.7 \%$ single due to divorce or separation, $4.4 \%$ long-term partnered or living with someone, $3.2 \%$ currently not in a romantic relationship, and $1.3 \%$ widowed. Lastly, reported length of time serving as a foster parent 
in the foster care system ranged from one to $20+$ years with a mean of 5.36 years $(S D=$ $5.10)$.

\section{Measures}

The anonymous online survey consisted of measures concerning demographics, parent-child communication, family communication, family identity, child adjustment, and relational well-being (see Appendix C for a full list of survey items). Descriptive statistics, reliability coefficients, and correlations are provided in Table 1.

\section{Shared Family Identity}

A six-item measure gauged the extent to which foster parents identified as members of the same family as their foster child (e.g., "I feel as if we are members of the same group"; "I feel as if we are members of separate groups"; Soliz \& Harwood, 2006). Possible responses for all items range from (1) strongly disagree to (7) strongly agree with high scores representing high levels of the construct.

\section{Communicative Openness}

A 15-item measure determined foster parent's perceptions of communicative openness with their foster child (e.g., "I am a good listener when it comes to my child's thoughts and feelings about being placed in foster care"; "I make it easy for my child to ask questions about his/her foster care placement or about his/her birth parent(s)"; Brodzinsky, 2006). Possible responses for all items range from (1) strongly disagree to (7) strongly agree with high scores representing high levels of the construct.

\section{Family Communication Patterns}

The Revised Family Communication Patterns instrument (RFCP: Ritchie \& Fitzpatrick, 1990) contains two subscales measuring parent's perceptions of conformity 
and conversation orientation. The RFCP is a 26-item measure that asks respondents to evaluate the extent to which their family communication patterns reflect conversation (15 items, e.g. "I like to hear my child's opinions, even when s/he doesn't agree with me") and conformity orientations (11 items, e.g. "I sometimes become irritated with my child's views if they are different from mine"). Possible responses for all items ranged from (1) strongly disagree to (7) strongly agree with high scores representing high levels of conformity and conversation orientation.

\section{Child Adjustment}

The Strengths and Difficulties Questionnaire (e.g. SDQ; Goodman, 1997) consists of two subscales that assess parent's perceptions of children's behavioral adjustment. The SDQ also takes into account child's age. As such, two separate versions of the SDQ were utilized in the present study: the one for children aged four through ten as well as the one provided for children aged 11-18. Each version of the SDQ consists of 25-items that measure children's exhibited behavioral strengths (5 items, e.g. "often offers to help others (parents, teachers, other children)"; “considerate of other people's feelings and difficulties" (20 items, e.g., "often loses temper; constantly fidgeting and squirming"; “easily distracted, concentration wanders"). Possible responses for all items ranged from (1) not true to (3) absolutely true with high scores representing high levels of the construct.

\section{Relational Closeness}

A 17-item measure gauged foster parent's relational closeness with his/her foster child (e.g., "How important is your relationship with your child in your life?"; "How often do you show your child affection?”; Miller \& Lefcourt, 1982). Possible responses 
for all items ranged from (1) not a lot to (5) a lot with high scores representing high levels of the construct.

\section{Conclusion}

The present study was interested in defining what sustains and predicts communication in current foster families. To reach these goals, recruited foster parents completed an anonymous quantitative survey that assessed parent's perceptions of parentchild communication, family communication, family identity, child adjustment, and relational well-being. Zero-order correlations and regression analyses were utilized to obtain the results and will be presented in the next chapter. 


\section{CHAPTER III: RESULTS}

All statistical analyses were conducted using SPSS version 21.0. An alpha level of .05 was retained for all statistical analyses performed. Preliminary data analysis revealed three demographic variables were significantly related to key constructs and were thus used as controls in the regression analyses: child age, parent sex, and the number of foster children the foster parent had cared for in total (see Table 1). For regression analyses parent sex was recoded such that males $=1$ and females $=0$ (see Methods).

Zero-order correlations were run on all key variables (see Table 1) and provided results to assess $\mathrm{H} 1-\mathrm{H} 3$ and RQ1-RQ2. H1 was supported in that shared family identity was positively associated with relational closeness between foster parent and child. With regard to RQ1, no significant relationship was found between the constructs of communicative openness and shared family identity. $\mathrm{H} 2$ was partially supported in that communicative openness was positively associated with child's perceived strengths as well as relational closeness between foster parent and child. However, there was not a significant relationship between communicative openness and child's perceived difficulties. $\mathrm{H} 3$ was supported in that conversation orientation was positively associated with perceptions of shared family identity. No significant relationship between the constructs of conformity orientation and shared family identity emerged; therefore, RQ2 was not supported.

H4 and RQ3 examined the degree to which conversation and conformity orientation, respectively, moderated the relationship between communicative openness and a) child strengths, b) child difficulties and c) relational closeness between foster parent and child. To test $\mathrm{H} 4$ and RQ3, the interaction effects for both conversation and 
conformity orientation were assessed based on Hayes' (2013) recommendation for testing moderation in regression analysis via PROCESS.

Using Hayes' (2013) PROCESS macro in SPSS, communicative openness and each of the moderators (e.g., conversation or conformity orientation) were entered in an ordinary least squares regression model with each of the dependent variables (e.g., child strengths, child difficulties, and relational closeness). Based on the significant correlations (see Table 1), foster child age, parent sex, and how many foster children the foster parent had cared for in total were entered as controls into each regression.

PROCESS automatically mean-centers the variables and creates an interaction term that is entered into the regression equation with the mean-centered predictor variables.

If a significant interaction emerged, two functions of PROCESS were employed to probe the interaction. First, regression slopes $(b)$ were observed at three levels of the moderating variable (one standard deviation above the mean, the mean, and one standard deviation below the mean). In doing so, the relationship between communicative openness and the dependent variable (e.g., child strengths, child difficulties, and relational closeness) were examined to assess how each varied based on the level of the moderator. Second, the Johnson-Neyman $(\mathrm{J}-\mathrm{N})$ technique was utilized to identify the specific regions within the range of the moderator variable (e.g. conversation orientation or conformity orientation) in which the effect of the independent variable (e.g. communicative openness) upon the dependent variable (e.g., child strengths, child difficulties, and relational closeness) was significant (Hayes \& Matthes, 2009). The J-N technique affords additional precision in probing interactions due to the precise nature of the decomposition method. 
Three regression models were run to assess $\mathrm{H} 4$, which predicted that the relationship between communicative openness and each of the dependent variables (e.g., child strengths, child difficulties, and relational closeness) would be moderated by the degree of perceived conversation orientation. When strengths served as the dependent variable, the model was significant, $F(6,146)=4.57, R^{2}=.16, p<.001$. However, there were no significant predictors in the model and therefore no significant interaction effect emerged $(\beta=.01, t=.17, p>.05)$. Thus, H4a was not supported. When difficulties served as the dependent variable the model was not significant, $F(6,146)=1.34, R^{2}=$ $.05, p>.05)$. There were no significant predictors in the model and therefore no significant interaction effect emerged $(\beta=.01, t=.17, p>.05)$. Thus, $\mathrm{H} 4 \mathrm{~b}$ was not supported. When relational closeness served as the dependent variable the model was significant, $\left.F(6,146)=10.97, R^{2}=.31, p<.001\right)$. However, adding the interaction term did not significantly add to the model $(\beta=.03, t=.55, p>.05)$. Therefore, H4c was also not supported. In sum, no support was found for H4.

Three regression models were also run to assess RQ3, which sought to explore if the relationship between communicative openness and each of the dependent variables (e.g., child strengths, child difficulties, and relational closeness) was moderated by conformity orientation. RQ3a examined the degree to which the relationship between communicative openness and child strengths would be moderated by conformity orientation. The model was significant, $F(6,146)=3.36, R^{2}=.12, p<.001$. Conformity orientation was a significant predictor in the model $(\beta=.79, t=2.11, p<.05)$. Communicative openness was also a significant predictor in this model $(\beta=.70, t=2.85$, $p<.01)$. Lastly, the interaction was significant such that conformity orientation emerged 
as a significant moderator between communicative openness and child strengths $(\beta=-$ $.15, t=-2.23, p<.05)$. When conformity orientation was at the mean $(\beta=.18, t=2.99, p$ $<.01)$ as well as one standard deviation below the mean $(\beta=.31, t=3.56, p<.001)$, the relationship between communicative openness and child strengths was significant. However, when conformity orientation was one standard deviation above the mean, the relationship between communicative and child strengths was no longer significant $(\beta=$ $.05, t=.61, p>.05)$. This demonstrates that the relationship between communicative openness and child strengths is strongest when conformity orientation is low. Regions of significance generated by the J-N technique show one key transition point. When conformity orientation is 3.72 or higher, there is no relationship between communicative openness and child strengths. Therefore, support was found for RQ3a.

RQ3b sought to determine if the relationship between communicative openness and child difficulties would be moderated by conformity orientation. The model was not significant $F(6,146)=1.07, R^{2}=.04, p>.05$. As such, there were no significant predictors and the interaction was not significant $(\beta=-.15, t=-2.23, p>.05)$. Therefore, neither the model nor the interaction was significant when child difficulties served as the dependent variable. As such, RQ3b was not supported.

RQ3c sought to determine the relationship between communicative openness and relational closeness would be moderated by conformity orientation. The model was significant $F(6,146)=4.69, R^{2}=.16, p<.001$. However, the interaction was not significant $(\beta=.01, t=.23, p>.05)$. Thus, RQ3c was not supported. In sum, RQ3 was partially supported due to the significance found with regard to RQ3a.

H5 examined the degree to which the relationship between conformity orientation 
and each of the dependent variables (e.g., child strengths, child difficulties, and relational closeness) would be moderated by the degree of conversation orientation. To test H5, the interaction effect for conversation orientation was also assessed based on Hayes' PROCESS macro in SPSS. Conformity orientation and conversation orientation were entered into an ordinary least squares regression model with each of the dependent variables (e.g., child strengths, child difficulties, and relational closeness). Based on the significant correlations (see Table 1), foster child age, parent sex, and how many foster children the foster parent had cared for in total were entered also used as controls in this analysis. If a significant interaction emerged, the same two functions in PROCESS (e.g., regression slopes (b) at the three levels and the $\mathrm{J}-\mathrm{N}$ technique) were employed to probe the interaction.

Three regression models were run to assess $\mathrm{H} 5$, which predicted that the relationship between conformity orientation and each dependent variable (e.g., child strengths, child difficulties, and relational closeness) would be moderated by the degree of perceived conversation orientation. H5a examined the degree to which the relationship between conformity orientation and child strengths would be moderated by conversation orientation. The model was significant $F(4,146)=4.56, R^{2}=.16, p<.001$. However, no significant predictors or interaction emerged $(\beta=-.04, t=-.60, p>.05)$. Therefore, neither the model nor the interaction was significant when child strengths served as the dependent variable. As such, H5a was not supported.

H5b examined the degree to which the relationship between conformity orientation and child difficulties would be moderated by conversation orientation. The model was not significant $F(4,146)=1.37, R^{2}=.05, p>.05$. Additionally, no 
significant predictors or interaction emerged $(\beta=-.01, t=-.31, p>.05)$. Therefore, neither the model nor the interaction was significant when child difficulties served as the dependent variable. As such, H5b was not supported.

H5c examined the degree to which the relationship between conformity orientation and relational closeness would be moderated by conversation orientation. The model was significant $F(6,146)=12.21, R^{2}=.33, p<.001$. Conformity orientation was a significant predictor in the model $(\beta=-.76, t=-2.36, p<.05)$. Further, the interaction was significant such that conversation orientation emerged as a significant moderator between conformity orientation and relational closeness $(\beta=.13, t=2.35, p<.05)$. When conversation orientation was at the mean as well as one standard deviation above and below the mean, the relationship between conformity orientation and relational closeness were not significant $(p>.05)$. However, the rigor inherent to the $\mathrm{J}-\mathrm{N}$ technique does allow for significant effects to be seen, at roughly two standard deviations above and below the mean of conformity orientation. Regions of significance generated by the J-N technique showed two key transition points. First, when conversation orientation is 6.68 or higher, the relationship between conformity orientation and relational closeness is approaching significance $(.11<\beta<.15 ; .08<p<.05)$. Thus, the association between conformity orientation and relational closeness is significantly positive when conversation orientation is 6.68 or above. Second, when conversation orientation is lower than 4.85 , the relationship between conformity orientation and relational closeness is significant $(-.13<\beta<-.26 ; .02<p<.05)$. This demonstrates that the association between conformity orientation and relational closeness is significantly negative when conversation orientation is below 4.85. Thus, support was found for H5c; in sum, H5 is 
partially supported.

Theoretical extensions and contributions from the current study, as well as how fostering a sense of shared family identity transpires in the foster family form, will be discussed in the following chapter. 


\section{CHAPTER IV: DISCUSSION}

The primary purpose of this study was two-fold: (1) to assess what predicts communication in foster families (e.g., shared family identity and communicative openness) and (2) to examine how communication and openness function in foster families (e.g., relate to child strengths, child difficulties, and relational closeness between foster parent and child). First, a brief summary of these findings will be presented. Second, theoretical contributions leading to theory advancement are discussed. Third, fostering a shared family identity in the foster family form will be considered. Lastly, directions for future scholarship on foster family communication, and the foster square more broadly, are set forth.

\section{Summary of Findings}

This study puts forth four main claims. First, in assessing what predicts communication in foster families, it was argued that shared family identity would be related to levels of relational closeness, communicative openness, and both conformity and conversation orientation within the foster family unit. Second, it was contended communicative openness would be related to foster child adjustment and relational wellbeing between foster parent and child. Third, the dimensions of conformity and conversation were each expected to interact with communicative openness to predict child adjustment and relational well-being. Fourth, the dimensions of conformity and conversation were expected to interact with each other to predict child adjustment and relational well-being. Results from the study provide insight into the validity of these claims. 
In regard to the first claim, it was found that shared family identity was positively related to relational closeness and conversation orientation. However, results indicated shared family identity was not significantly related to conformity orientation or the degree of openness exhibited in discussions with foster children about foster-related topics and emotions. No support was found in accordance with the second claim. Communicative openness was not positively related to child's strengths, child's difficulties, or relational closeness. However, in regard to the third claim, partial support was found. The relationship between communicative openness and child strengths was moderated by the degree of conformity orientation. Specifically, it was found that foster parents who were more communicatively open had a significant and positive impact on their child's exhibited strengths. However, if conformity orientation was emphasized to any degree, this relationship between these two constructs was no longer significant. Lastly, partial support was found for the fourth and final claim. Specifically, the relationship between conformity orientation and relational closeness was significantly impacted by both high and low degrees of conversation orientation. For parents who indicated high degrees of conversation orientation within the family, a positive relationship between conformity orientation and relational closeness emerged; for parents who indicated a particularly low degree of conversation orientation within the family, a negative relationship between conformity and relational closeness emerged.

Next, theoretical contributions leading to theory advancement will be discussed. Specifically, an evaluation of Family Communication Patterns theory and the Revised Family Communication Patterns instrument to the foster family context will be assessed. 


\section{Theoretical Contributions}

Family Communication Patterns theory (Koerner \& Fitzpatrick, 2002) and the Revised Family Communication Patterns instrument (RFCP: Ritchie \& Fitzpatrick, 2012) are both widely used in family communication research (Koerner \& Fitzpatrick, 2012; Reuter \& Koerner, 2008; Schrodt et al., 2008; 2009). By examining the role of conversation and conformity orientation and the predictive value of such constructs in the foster family form, this theory was extended to the foster family context. Through the extension of the theory and measure to this context, two important considerations for theory expansion surfaced: (1) taking into account child's developmental stage and (2) addressing the context-dependent nature of the RFCP instrument. Both theoretical contributions are contended and discussed in the following sections.

\section{Importance of Child Development}

Results from the present study indicated the dimensions of conformity and conversation orientation did not significantly impact or interact with several key constructs. It is possible this is a direct result of the measure not adequately accounting for variation in utilized family communication patterns due to child's developmental stage. As such, items on the RFCP, which measure the degree of conformity and conversation orientation in families, seem to be geared toward an older, more mature child population (i.e., "In our family we often talk about topics like politics and religion where some persons disagree with others"). Given the fact children reported on in this sample were fairly young $(M=8.08 S D=4.93)$, this likely played a part in some of the non-significant findings in the current study. It is unlikely parents of any family type broach topics such as politics with younger children due to the presumed correlation 
between child's current developmental stage and his/her capacity for understanding. The importance of taking into account child's developmental stage when assessing communication variables in families is further argued for by Wrobel and colleagues (2003) in their work on adoptive family communication.

Relative to adoptive communication but arguably applicable in the foster family context, Wrobel and colleagues developed the Family Adoption Communication Model (e.g. FAC-M, Wrobel et al., 2003; Nelson, 2014). The central premise behind the FAC-M is that as a child develops, so too does his/her capacity for understanding and discussing his/her adoption and adoption-related emotions and feelings. Because not all children are adopted (or fostered) as infants, the focus in the FAC-M is on the developmental stage of the child. In fact, as children's capacity for understanding grows, it is bi-directional communication from parent to child and child to parent, that actually allows for children's progression through various developmental stages (Manning, 2006; Wrobel et al., 2003). Further, it is possible that the child's perceived level of maturity and development may serve a role in parent's emphasis of either conformity or conversation orientations in any given interaction.

Thus, this critique leads to the recommendation for an extension of the RFCP instrument to better account for variability in child's development when assessing conversation and conformity orientation. Arguably, a measure that focuses more on child's developmental stage when assessing family communication patterns could prove fruitful. Therefore, despite the high reliability consistently achieved by the RFCP, Family Communication Patterns theory, specifically the RFCP, ought to be reassessed and extended to account for such child developmental differences in family communication. 


\section{Context-Dependent Nature of Family Communication Patterns}

With regard to the RFCP instrument, results of the current study indicate it may be especially important to take into account context when assessing family communication patterns. Specifically, results illustrate structural components of family

(i.e., family type, socio-economic status, etc.) may play an important role in the degree of conversation and conformity orientation exhibited by foster parents with his/her foster child.

Overall, findings from the present study reveal that conformity orientation relates to a number of child well-being outcomes. Specifically, families with high conformity tend to experience challenges in fostering positive outcomes for and with their child. In essence, if foster parents strive too hard to have foster children conform to beliefs, no matter how open they are about foster-related issues, children's exhibited strengths will no longer be affected. As such, foster parents must be particularly tactful in how they approach child adjustment when it comes to the degree they communicate and demand uniformity in beliefs with foster children. This tact may be specific to the foster family context and thus should be accounted for in theory. Therefore, the proposition to account for such context-dependency when assessing family communication patterns is set forth.

For example, with regard to specific items on the RFCP, it is possible foster parents in particular may feel some topics like politics and religion are taboo, given the fact children may already have an established set of beliefs courtesy of their birth family. In fact, Docan-Morgan (2011) found topic avoidance surrounding a similarly sensitive matter, race, was inherent in transracially adoptive families. Reasons for topic avoidance reported were self-protection and unresponsiveness (Docan-Morgan, 2011). This 
illustrates the potential for other families to avoid certain topics perceived as sensitive to one or more family members. Therefore, it is possible parents may experience comparable emotions when discussing issues perceived as similarly sensitive in the foster family context. Additionally, the ambiguity inherent to a temporary familial status may further serve as a barrier in foster parents emphasizing conformity orientation with their foster child. It is plausible foster parents feel the need to be more open to differences in children's beliefs in addition to including children while making decisions, both characteristic of conversation orientation, due to the ambiguous nature of the relationship.

As such, one primary way in which the current study contributes to the advancement of Family Communication Patterns theory is through the recognition that structural components, such as (lack of) genetic relatedness, and possibly even religion, race, or socio-economic status of the family likely have a bearing on how parents and children communicate based on family type or due to other social identities that may be present in the family. In essence, because it has been revealed that foster families may experience unique issues that the RFCP instrument should account for, it is plausible there are other contexts in which the measure simply cannot get at unique issues families face. As such, the context-dependent nature of Family Communication Patterns theory and the RFCP instrument should be explored in future research.

\section{Fostering a Shared Family Identity}

Establishing a common ingroup via shared family identity benefited foster families in fundamental ways in the current study. While shared family identity was not associated with the constructs of conformity orientation or communicative openness, and assessing the impact of shared family identity to child strengths and child difficulties was beyond the scope of this study, unique understandings of how foster families perceive 
and communicate based on a perceived common familial group surfaced. Namely, the importance of openness, foster parent's role in promoting pro-social development, and the significance of family belongingness emerged. These three aspects illustrate how fostering "family" transpires and the importance of feeling like family to individual and relational functioning in this family form.

\section{Importance of Openness}

Openness proved paramount in the foster family context, both at the individual and relational levels, in promoting positive child outcomes. Chiefly, the degree to which foster parents emphasized conversation orientation and communicative openness with their foster children served a distinct role in foster family functioning. The important role openness serves in the foster family form is elaborated on through an examination of conversation orientation, communicative openness, and the interaction of the two on shared family identity and relational closeness.

First, conversation orientation was positively correlated with shared family identity such that the more open, free-flowing the dialogue in foster family interactions, the more the foster parent reported feeling as if the foster child was a member of the same family. Additionally, foster parents who were consistent in the degree to which they emphasized both conformity and conversation orientations with his/her foster child had implications with regard to relational closeness. Specifically, foster parents who assumed the consensual parenting style (e.g. high in conformity and high in conversation) reported feeling closer to his/her foster child. It is plausible these foster parents feel the need to be highly open in order to emphasize conformity in order for their communication with their foster children to have positive relational outcomes. On the other hand, foster parents 
who assumed the laissez-faire parenting style (e.g. low in conversation orientation and low in conformity orientation) reported feeling less close to his/her foster child. Parents of this familial type characteristically do not tend to children's emotions or engage much at all with the child (Koerner \& Fitzpatrick, 2012). As such, it is likely foster parents that approach parenting in this manner do not have enough of a history of significant communicative events built up with their foster child to afford the establishment of a close bond.

These findings provide insight into the pertinence of creating an open climate in which both dialogue and conformity in beliefs are simultaneously encouraged in the foster family context. It is plausible by not only being open but also encouraging the child to conform to beliefs and ideals held by foster parents makes all members of the foster family, in general, feel closer and more like family despite the temporal nature of foster care. Much like the common ingroup identity model illustrates, it may be that these interactions, which acknowledge one's individual identity while simultaneously building a shared identity, aid in fostering a close relationship (Gaertner \& Dovidio, 2000).

Second, in response to a research call by Jones \& Hackett (2008), underpinnings that may facilitate communicative openness and shared family identity in foster families were examined. No significant relationship emerged between communicative openness and shared family identity in the current study. Therefore, while conversation orientation was positively correlated with shared family identity, foster communicative openness was not correlated with shared family identity. This suggests that while families must be open to discussing a multitude of topics in order to secure a sense of shared family identity, being more open about foster-related issues and emotions may not carry the same weight 
in fostering perceptions of "family" in this sample. While assessing the specifics of what foster parents do and do not discuss with their child was beyond the capacity of this study, it is possible the content of the foster issues parents choose to discuss with their foster child may play a vital role. In fact, some topics pertaining to children's placement in foster care may just be too traumatizing to openly discuss (see Docan-Morgan, 2011). It would be helpful to be able to gauge the child's experienced trauma prior to entering the foster care system in order to assess not only the impact of communication but also other potential reasons for lack of openness relating to certain topics.

Lastly, despite the fact openness was associated with many positive outcomes for foster parents and children, the interaction of communicative openness and conversation orientation on a) child strengths, b) child difficulties, and c) relational closeness between foster parent and child were all non-significant in the current study. One reason for these non-significant findings is the possibility that the constructs of conversation and communicative openness overlapped considerably. If foster parents are more willing to openly discuss a variety of topics in general, they may also be more willing to openly discuss foster-related issues and emotions with the foster child. As such, it is possible these two constructs were measuring virtually the same thing in this interaction, thus any significant interactional effects could not be adequately determined.

In essence, the more open and warm the conversations were between parent and child, the more they felt like a family. Much like Ellingsen and colleagues found, it is likely foster parents need to be open to including the birth family as part of their definition of family in order for foster children to feel as if they belong (2012). Further, Berry (1991) discovered that children in California who had contact with their birth 
families upon coming out of the foster system exhibited better behavior. As such, by promoting communication about a wide array of topics, it is likely more conversations were broached concerning the child's birth family. There are no data at this time to help determine which foster families and children might benefit, and under what conditions, from continued open communication with the birth family while currently in the foster

family (Brodzinsky, 2005). Therefore, future research should attempt to assess if and how foster parents utilize communicative openness with his/her current foster child.

Specifically, exploring the effect of continued contact with the birth family on the degree of communicative openness exhibited in foster families and the effect of such levels of openness on children's adjustment and relational outcome is worthy of assessment.

\section{Foster Parent's Role in Pro-Social Development}

Although little can be inferred about how communication may impact children's hardships and negative behaviors in light of the results provided by the current study, it was determined that the foster family environment can strengthen children and allow them to flourish. In fact, results indicate foster parents play a vital role in fostering children's pro-social development. Communicative openness, in particular, was beneficial in facilitating close family connections and child's perceived strengths. These results suggest the construct of communicative openness positively impacts pro-social constructs (e.g. child's strength and relational closeness), but potentially has no effect on anti-social constructs (e.g. child difficulties). Therefore, while findings of the current study provide valuable suggestions for foster parents in promoting pro-social individual and relational outcomes overall, still much less is known about how communication might influence the difficulties these foster children experience. 
Many of the foster parents in the current study reported children had moderate to low child adjustment issues. In fact, the data was skewed such that a majority of children were in the range of not experiencing difficulties to somewhat experiencing difficulties $(M=1.7, M d n=1.5, S D=.38)$. Moreover, given that foster children often come into the system experiencing social, emotional, and behavioral difficulties, it is possible foster children are only experiencing "some" of the difficulties due to the stability and security afforded by the foster family environment (Ackerman \& Dozier, 2005; Legault, Anawati, \& Flynn, 2006; Luke \& Coyne, 2008).

Further, the mean age (e.g. 8 years old) of foster children in the current sample could have attributed to the lack of significant findings. Research has shown difficulties often resurface in adolescence for foster children. More specifically, if a child "ages out" of the foster care system, that is reaches the age of 18 while in the foster care system without receiving a permanent placement with a family, mild to severe behavioral, social, and emotional difficulties are anticipated throughout the life course (Mekonnnen et al., 2009; Minnis et al., 2006; Oswald et al., 2010; Simms, 2000). Consequently, it is possible the more serious difficulties that arise during adolescence could not adequately be gauged in the current study given the mean sample age of foster children. As such, future research could greatly benefit from examining the implications of specific communication behaviors (e.g. conformity orientation, communicative openness, conformity orientation) on both younger and older foster children's overall adjustment.

\section{Belongingness in the Foster Family}

Arguably the most important contribution of the current study, results indicate that foster parents view his/her foster child as part of their family despite the temporal 
nature of foster family relationships. As such, although foster relationships are designated as "temporary," foster parents and children are really feeling like family. Namely, the tendency for the data to be highly positively skewed on the shared family identity variable $(M=6.29)$ suggests that, although temporary in status by law, foster parents still strongly feel their foster child and themselves are part of the same family. This challenges traditional assumptions surrounding what "family" is (see Floyd et al., 2006; Suter \& Ballard, 2009) and calls for an expansion of current scholarly definitions to go beyond rights, genetics, and a long-term status when understanding "family."

Findings from the current study may further help to explain why no relationships emerged with regard to foster children's perceived difficulties in adjustment. As the Common Ingroup Identity Model has revealed, differences in a family can be transcended through perceptions of a common familial identity (Soliz \& Harwood, 2006). Therefore, by coming together and building a shared relational culture, it is likely foster parents were able to develop harmonious relationships with their foster children which eradicated some of the negative effects foster children generally experience (Oswald et al., 2000). Further, in achieving a more inclusive sense of "we" was related to positive outcomes in the sample. As such, many foster parents are feeling like family and this is promoting pro-social outcomes at both the individual and relational levels.

Also, foster parents who reported feeling closer to their foster child also reported feeling as if his/her child belonged to the same family as themselves across a variety of interactional contexts. It is plausible for foster parents who became closer to foster children it felt more natural to embrace the child as part of the family, in light of the temporary nature of foster family relationships. It is also possible parents who find 
themselves closer and view their foster child as part of the family have been together for a significant amount of time. It would be worth knowing, in general, how long it takes foster parents and children to establish such close bonds and under what other circumstances.

In sum, although a number of the findings provided are correlational in nature and do not allow for causal inferences, a number of implications and directions for future research were able to emerge from data analysis. Now that significant relationships between constructs have been identified, future research can more confidently explore causal relationships. This will be helpful in being able to generalize results to the greater population as well as communicate and provide suggestions for best practices to foster parents, foster agencies, and the foster care system at large.

\section{Future Research Agenda for Foster Family Communication}

The results of the current study provided for specific insights and conclusions to be drawn on the role of communication in the foster family context. Refreshing new perspectives on how communication sustains and functions in the foster family form were afforded. Thus, several ripe areas for future family communication scholarship are proposed.

First, future research ought to explore the direct effects of child age on children's outcomes. As was aforementioned, there are likely distinct differences between younger and older children's experiences in and perceptions of foster care. Being that the current study assessed children from infancy up to 18 years old, it would be interesting to further explore the ways in communication between foster parent and child changes as the child ages and develops. Future research should examine these potential age differences on 
both individual and relational outcome variables through more nuanced analyses. Specifically, conducting longitudinal research on the foster family form would be beneficial in tracing the potential impacts of foster family communication, both positive and negative, on individual and relational functioning over time.

Second, it is worth examining if foster children who are placed in foster care for similar reasons experience communication within their foster families similarly. Examining the potential differences between adoptive and foster communication could prove beneficial in understanding how and under what type of communicative climate each family type and member thrives. It is possible there are specific communication strategies and techniques that work better for children based on that child's past experience with his/her birth family and/or reason for placement. As such, placementspecific communication strategies for bettering child outcomes could potentially be revealed through future research.

In line with bettering outcomes, another area for research is the impact of being placed with or without siblings on foster children's short and long-term outcomes. Specifically, family communication scholars should assess how siblings may alter the impact of foster square communication on individual and relational outcome variables. For instance, a comparison study on foster children placed with and without one or more of their siblings could provide rich details into the influence of sibling placements. It would be interesting to assess the differences not only between those placed with and without siblings, but also to be able to compare foster children placed with all siblings versus being placed in a foster family with only some. 
Exploring some of the inherent tensions in the foster square is also worthy of future assessment. One place to start could be an exploration of themes and tensions between foster families', birth families', foster child's and agency worker's definitions and perceptions of family. Specifically, the impact of emergent themes and tensions on child adjustment and individual and relational functioning could prove fruitful to explore. Seeing this full picture could provide great insights into the complex web of interactions inherent to the foster square. It is likely researchers would need to recruit foster families through agencies for such an analysis to occur. Again, this addresses one of the three plausible reasons set forth why the foster family form remains understudied: it is difficult to assess (Patrick, 2012). To address difficulty in accessing this family type, a couple of suggestions are offered.

It is imperative researchers build trust with foster care agencies, support groups, and organizations where research on the foster square could potentially be easier to conduct. Suggestions for gaining agency's trust include providing the approval letter in addition to all documentation submitted to your institutions Institutional Review Board (IRB). Additionally, including a letter from your institutions' IRB confirming any identifying information provided on behalf of the participant will remain confidential and not be revealed in the write-up of the study could prove useful.

More, it is paramount researchers do everything possible to ensure participants anonymity is guaranteed. As we know, the circumstances regarding children's placements are often traumatizing and are likely considered private and sensitive matters to discuss (Holtan et al., 2005; McWey et al., 2010; Ryan et al., 2007). Therefore, ensuring the protection of participant's identities and any identifying information 
disclosed is particularly important when researching the foster square. Similarly, participating in research pertaining to one's experiences with the foster care system may seem risky and potentially traumatizing in and of itself for some individuals. However, researchers can account for most of these risks to privacy in the research design.

With qualitative methods, guaranteeing participant's right to refuse answering any question is primary. Lastly, offering debriefing services after interviews and/or focus groups is another possible method to prevent against any potential harm that may come to individuals as a direct result of participation. With quantitative methods, allowing participants the right to refuse to answer any question is imperative. Further, informing participants that he/she may exit the survey or experiment at any time would be crucial in further protecting against any harm that may come to individuals as a direct result of participation.

In sum, there are many boundaries and areas inherent to the foster family structure (i.e., appropriate levels of affection, closeness, openness, etc.) as well as studying foster families (i.e., the applicability of existing measures and instruments to tap into the foster family context) that are not clearly defined to-date. Especially when it comes to family communication patterns and communicative openness, structural component differences appear to be especially salient to assess. It is possible an exploratory study focusing on foster parent's cognitions and motivations behind communicative behaviors would allow future researchers to understand how foster parent's thoughts are translating into communicative acts with his/her foster child. In this regard, perhaps a better way of gauging the communicative high and low boundaries of key communication constructs in foster families would be possible. 


\section{Limitations}

The homogeneity seen in the sample in terms of sex and race is an inherent limitation that must be considered when making inferences about the greater foster parent population. The majority of the foster parents in the current sample were Caucasian $(81 \%)$ and female (98\%). Further researchers could strive to obtain an overall more diverse sample in which to assess relevant constructs. It is likely random sampling, rather than convenience sampling, would allow for a more diverse sample to emerge.

Additionally, although there were just eight men in the current sample, male foster parents scored significantly higher than women on the construct of conformity orientation. As such, parsing out sex differences among foster parents with regard to reported family communication patterns and their effect on individual and relational outcomes is worth evaluating in future research on foster parents specifically.

\section{Conclusion}

The present study provided a number of insights into the communicative dynamics inherent to the foster parent-child relationship and the effects of such communication at both the individual and relational levels. Using Family Communication Patterns theory, specific conclusions were drawn about what predicts communication in foster families and how communication functions in the foster family context.

These findings illuminated two key theoretical extensions for consideration: (1) accounting for differences in child development in the RFCP instrument and (2) accounting for differences in family structures with regard to family type (i.e., foster, blended, adoptive, etc.) and other family-specific characteristics (i.e., socioeconomic status, religion, race, current relationship status, etc.) when assessing family 
communication patterns. Additionally, understanding how foster parents "do family" and achieve a sense of shared family identity through openness, promoting children's strengths, and fostering feelings of belongingness all offer a variety of fresh new avenues for future scholarship on foster family communication. 


\section{REFERENCES}

Achenbach, T. M. (1991) Manual for the child behavior checklist 4-18 and 1991 profile. Burlington, VT: University of Vermont Department of Psychiatry.

Ackerman, J. P. \& Dozier, M. (2005). The influence of foster parent investment on children's representations of self and attachment figures. Applied Developmental Psychology, 26, 507-520.

AFCARS Report: Preliminary FY 2012 Estimates as of July 2013. (Adoption and Foster Care Analysis and Reporting System). Retrieved from http://www.acf.hhs.gov/sites/default/files/cb/afcarsreport20.pdf

Andersson, G. (2009) Foster children: a longitudinal study of placements and family relationships. International Journal of Social Welfare, 18, 13-26.

Anyan, S.E. \& Pryor, J. (2002) 'What is family: adolescent perceptions.' Children \& Society, 16, 306-315.

Banker, B. S., \& Gaertner, S. L. (1998). Achieving stepfamily harmony: An intergrouprelations approach. Journal of Family Psychology, 12(3), 310-325. doi:10.1037/0893-3200.12.3.310

Baxter, L. A. (2004). Relationships as dialogues. Personal Relationships, 11, 1-22.

Beck, S. J., \& Ledbetter, A. M. (2013). The influence of parent conflict style on children. Personal Relationships, 20(3), 495-510.

Berry, M. (1991). The practice of open adoption: Findings from a study of 1,396 families. Children and Youth Services Review, 13, 379-395. 
Brodzinsky, D. (2006). Family Structural Openness and Communication Openness as Predictors in the Adjustment of Adopted Children. Adoption Quarterly, 9(4), 118.

Brodzinsky, D. M. (2005). Reconceptualizing openness in adoption: Implications for theory, research, and practice. In M. Brodzinsky \& J. Palacios (Eds.), Psychological issues in adoption: Research and practice (pp. 145-166), Westport, CT: Praeger Publishers.

Brodzinsky, D. M., \& Pinderhughes, E. (2002). Parenting and child development in adoptive families. In M. H. Bornstein (Ed.), Handbook of parenting: Vol. 1. Children and parenting ( $2^{\text {nd }}$ ed., pp. 279-311). Mahwah, NJ: Lawrence Erlbaum Associates.

Brown, J. D. (2008). Foster parent's perceptions of factors needed for successful foster placements. Journal of Child and Family Studies, 17(4), 538-554.

Byrd, M. M., \& Garwick, A. W. (2006). Family identity: Black-White interracial family health experiences. Journal of Family Nursing , 12, 22-37.

Clausen, J. M., Landsverk, J., Ganger, W., Chadwick, D., \& Litrownik, A. (1998). Mental health problems of children in foster care. Journal of Child and Family Studies, 7, 283-296.

Denuwelaera, M. \& Bracke, P. (2007). Support and conflict in the foster family and children's well-being: A comparison between foster and birth children. Family Relations, 56, 67-79. 
Colaner, C. W. \& Galvin, K. (2013). Created through law and language: Communicative complexities of adoptive families. In K. Floyd \& M. Morman (Eds.). Widening the family circle ( $2^{\text {nd }}$ ed.). Thousand Oaks, CA: Sage.

Colaner, C. W., \& Kranstuber, H. (2010). "Forever kind of wondering": Communicatively managing uncertainty in adoptive families. Journal of Family Communication, 10(4), 236-255.

Docan-Morgan, S. (2010). Korean adoptees' retrospective reports of intrusive interactions: Exploring boundary management in adoptive families. Journal of Family Communication, 10(3), 137-157.

Docan-Morgan, S. (2011). “They don’t know what it's like to be in my shoes”: Topic avoidance about race in transracially adoptive families. Journal of Social and Personal Relationships, 28(3), 336-355.

Ellingsen, I. T., Stephens, P., \& Størksen, I. (2012). Congruence and incongruence in the perception of 'family' among foster parents, birth parents and their adolescent (foster) children. Child \& Family Social Work, 17(4), 427-437.

Ellingsen, I.T., Shemmings, D. \& Størksen, I. (2011) The concept of 'family' among Norwegian adolescents in long-term foster care. Child and Adolescents Social Work, 28, 301-318. doi: 10.1007/s10560-011-0234-0.

Ferguson, S. J. (Ed.). (2007). Shifting the center: Understanding contemporary families. (3 $3^{\text {rd }}$ Ed.) Boston: McGraw-Hill.

Floyd, K., Mikkelson, A. C., \& Judd, J. (2006). Defining the family through relationships. In L. H. Turner \& R. West (Eds.), The family communication sourcebook (pp. 21-39). Thousand Oaks, CA: Sage. 
Friedlander, M. L. (1999). Ethnic identity development of internationally adopted children and adolescents: Implications for family therapists. Journal of Marital and Family Therapy, 25, 43-60.

Freundlich, M., \& Wright, L. (2003). Post-permanency services. Retrieved July 6, 2004, from Casey Family Programs Center for Resource Family Support website: http://www.casey.org/NR/rdonlyres/A96DC62B-190E-4F5CA21B984B0269C8E0/123/post_permanency_services.pdf

Gaertner, S. L. \& Dovidio, J. F. (2000). Reducing intergroup bias: The Common Ingroup Identity Model. Philadelphia, PA: Psychology Press.

Gaertner, S. L. \& Dovidio, J. F. (2005), Understanding and addressing contemporary racism: From aversive racism to the Common Ingroup Identity Model. Journal of Social Issues, 61, 615-639. doi: 10.1111/j.1540-4560.2005.00424.x

Galvin, K. M. (2003). International and transracial adoption: A communication research agenda. Journal of Family Communication, 3, 237-253.

Galvin, K. M. (2006). Diversity's impact on defining the family: Discourse-dependence and identity. In L. H. Turner \& R. West (Eds.), The family communication sourcebook (pp. 3-19). Thousand Oaks, CA: Sage.

Gardner, H. (1998) The concept of family: perceptions of adults who were in long-term out-of-home care as children. Child Welfare, 77, 681-700.

Goodman, R. (1997). The Strengths and Difficulties Questionnaire: A research note. Journal of Child Psychology and Psychiatry, 38, 581-586.

Grotevant, H. D., Fravel, D. L., Gorall, D., \& Piper, J. (1999). Narratives of adoptive parents: Perspectives from individual and couple interviews. Monographs of the 
Society for Research in Child Development, 64, 69-83.

Hayes, A. F. (2013). PROCESS: A versatile computational tool for observed variable mediation, moderation, and conditional process modeling [White paper]. Retrieved from http://www.afhayes.com/public/process2013.pdf.

Hayes, A. F., \& Matthes, J. (2009). Computational procedures for probing interactions in OLS and logistic regression: SPSS and SAS implementations. Behavior Research Methods, 41, 924-936. doi: 10.3758/BRM.41.3.924

Holtan, A., Ronning, J. A., Handegayrd, B. H., \& Sourander, A. (2005). A comparison of mental health problems in kinship and nonkinship foster care. European Child \& Adolescent Psychiatry, 14, 200-207.

Johnson, P. R., Yoken, C., \& Voss, R (1995). Family foster care placement: the child's perspective. Child Welfare, 74, 959-974.

Jonson-Reid, M. (1998). Youth violence and exposure to violence in childhood: An ecological review. Aggression and Violent Behavior, 3, 159-179.

Jones, C., \& Hackett, S. (2008). Communicative openness within adoptive families: Adoptive parents' narrative accounts of the challenges of adoption talk and the approaches used to manage these challenges. Adoption Quarterly, 10(3-4), 157178.

Kirk, D. (1964). Shared Fate. A Theory of Adoption and Mental Health. New York: Free Press.

Koerner, A. F., \& Fitzpatrick, M. A. (2002). Toward a theory of family communication. Communication Theory, 12(1), 70-91. doi: 10.1111/j.1468-2885.2002.tb00260.x 
Koerner, A. F., \& Fitzpatrick, M. A. (2002). Understanding family communication patterns and family functioning: The roles of conversation-orientation and conformity-orientation. Communication Yearbook, 26, 36-68.

Koerner, A., \& Fitzpatrick, M. (2006). Family communication patterns theory: A social cognitive approach. In D. Braithwaite, \& L. Baxter (Eds.), Engaging theories in family communication: Multiple perspectives (pp. 50-66). Thousand Oaks, CA: Sage.

Koerner, A. F., \& Fitzpatrick, M. A. (2012). Communication in intact families. In A. L. Vangelisti (Ed.), Handbook of family communication (pp. 129-143). New York, NY: Routledge.

Kohler, J.K., Grotevant, H.D. \& McRoy, R.G. (2002). Adopted adolescents' preoccupation with adoption: The impact on adoptive family relationships. Journal of Marriage and the Family, 64, 93-104.

Kools, S. M. (1997). Adolescent identity development in foster care. Family Relations, 263-271.

Legault, L., Anawati, M., \& Flynn, R. (2006). Factors favoring psychological resilience among fostered young people. Children and Youth Services Review, 28, 10241038.

Luke, N. \& Coyne, S. M. (2008). Fostering self-esteem: exploring adult recollections on the influence of foster parents. Child and Family Social Work, 13, 402-410. doi:10.1111/j.1365-2206.2008.00565.x 
Manning, L. D. (2006). "Presenting opportunities:" Communicatively constructing a shared family identity. International \& Intercultural Communication Annual, 29, 43-67.

McWey, L. M., Acock, A., \& Porter, B. E. (2010). The impact of continued contact with biological parents upon the mental health of children in foster care. Children and Youth Services Review, 32, 1338-1345.

Mekonnen, R., Noonan, K., \& Rubin, D. (2009). Achieving better health outcomes for children in foster care. Pediatric Clinics of North America, 56, 405-415.

Miller, R. S., \& Lefcourt, H. M. (1982). The assessment of social intimacy. Journal of Personality Assessment, 46, 514-518.

Minnis, H., Everett, K., Pelosi, A. J., Dunn, J., \& Knapp, M. (2006). Children in foster care: Mental health, service use and costs. European child \& adolescent psychiatry, 15(2), 63-70.

Neil, E. (2009). Post-adoption contact and openness in adoptive parents' minds: Consequences for children's development. British Journal of Social Work, 39(1), $5-23$.

Nelson, L. R. (2014). “Shaping” foster family communication: An application of the Family Adoption Communication Model. Paper presented at the 2014 Central States Communication Association Conference, Minneapolis.

Nickman, S.L. (1985). Losses in adoption: The need for dialogue. Psychoanalytic Study of the Child, 40, 365-398. 
Oswald, S.H., Heil, K., \& Goldbeck, L. (2010). History of maltreatment and mental health problems in foster children: A review of literature. Journal of Pediatric Psychology, 35, 462-472.

Patrick, D. (2012). Family communication and the foster care experience: the next frontier. Paper presented at the 2012 National Communication Association Conference, Orlando.

Rhodes, K. W., Orme, J. G., \& Buehler, C. (In press). A comparison of family foster parents who quit, consider quitting, and plan to continue fostering. Social Service Review.

Ritchie, L. D., \& Fitzpatrick, M. A. (1990). Family communication patterns: Measuring intrapersonal perceptions of interpersonal relationships. Communication Research, 17, 523-544.

Rittenour, C. (2012). Daughter-in-law standards for mother-in-law communication: Associations with daughter-in-law perceptions of relational satisfaction and shared family identity. Journal of Family Communication, 12(2), 93-110.

Rosnati, R., Iafrate, R., \& Scabini, E. (2007). Parent-adolescent communication in foster, inter-country adoptive, and biological Italian families: Gender and generational differences. Journal of Psychology, 42, 36-45.

Rueter, M. A., \& Koerner, A. F. (2008). The effect of family communication patterns on adopted adolescent adjustment. Journal of Marriage and Family, 70(3), 715-727.

Rutter, M. (2000). Children in substitute care: Some conceptual considerations and research implications. Children and Youth Services Review. Special issue: Child welfare research for the 21st century, 22, 685-703. 
Ryan, J. P., Herz, D., Hernandez, P. M., \& Marshall, J. M. (2007). Maltreatment and delinquency: Investigating child welfare bias in juvenile justice processing. Children and Youth Services Review, 29, 1035-1050.

Schrodt, P., Ledbetter, A. M., Jernberg, K. A., Larson, L., Brown, N., \& Glonek, K. (2009). Family communication patterns as mediators of communication competence in the parent_child relationship. Journal of Social and Personal Relationships, 26(6-7), 853-874.

Schrodt, P., Witt, P. L., \& Messersmith, A. S. (2008). A meta-analytical review of family communication patterns and their associations with information processing, behavioral, and psychosocial outcomes. Communication Monographs, 75(3), 248269.

Sinclair, I., Wilson, K. \& Gibbs, I. (2005) Foster Placements: Why They Succeed and Why They Fail. Jessica Kingsley Publishers, London.

Shin, S. H. (2005). Need for and actual use of mental health service by adolescents in the child welfare system. Children and Youth Services Review, 27(10), 1071-1083.

Simmel, C., Brooks, D., Barth, R., \& Hinshaw, S. (2001). Externalizing symptomatology among adoptive youth: Prevalence and pre-adoption risk factors. Journal of Abnormal Child Psychology, 29, 57-69.

Simms, M. D. (2000). Health care needs of children in the foster care system. Journal of the American Academy of Pediatrics, 106, 909-918.

Skinner-Drawz, B. A., Wrobel, G. M., Grotevant, H. D., \& Von Korff, L. (2011). The role of adoption communicative openness in information seeking among adoptees 
from adolescence to emerging adulthood. Journal of Family Communication, 11(3), 181-197.

Sobol, M.P., Delaney, S.\&Earn, B.M. (1994). Adoptees’ portrayal of the development of family structure. Journal of Youth and Adolescence, 32, 385-401.

Soliz, J., \& Harwood, J. (2006). Shared family identity, age salience, and intergroup contact: Investigation of the grandparent-grandchild relationship. This study was part of the first author's doctoral dissertation and portions of the study were presented at the National Communication Association annual meeting, Chicago, 2004. Communication Monographs, 73(1), 87-107.

Soliz, J. \& Rittenour, C.E. (2012) Family as an intergroup arena. In H. Giles. (ed.), Handbook of Intergroup Communication. New York: Routledge.

Soliz, J., Thorson, A. R., \& Rittenour, C. E. (2009). Communicative correlates of satisfaction, family identity, and group salience in multiracial/ethnic families. Journal of Marriage and Family, 71(4), 819-832.

Suter, E. A. (2008). Discursive negotiation of family identity: A study of US families with adopted children from China. Journal of Family Communication, 8(2), 126147.

Suter, E. A., \& Ballard, R. L. (2009). “How much did you pay for her?”: Decision making criteria underlying adoptive parents' responses to inappropriate remarks. Journal of Family Communication, 9(2), 107-125

Suter, E. A., Baxter, L. A., Seurer, L., \& Thomas, L. (2014). The dialogic construction of adoption in online foster adoption narratives. Communication Monographs, 81, 59-78. doi: 10.1080/03637751.2014.880791 
Thomas, L. (2013). “Once a foster child...”: Identity construction in former foster children's narratives. Paper presented at the 2012 National Communication Association Conference, Washington D.C.

Viadero, D. (2010). Foster children. Education Week, 29, 5.

Vuchinich, S., Ozretich, R. A., Pratt, C. C., \& Kneedler, B. (2002). Problem-solving communication in foster families and birthfamilies. Child Welfare, 81(4), 571-94. 


\section{APPENDIX A: RECRUITMENT SCRIPT}

Hello. My name is Leslie Nelson. I am a graduate student at the University of MissouriColumbia pursuing my Master's Degree in Communication. I'm conducting a study to learn more about foster parent communication and well-being. This study will require you to complete an online survey. The survey will take approximately 30 minutes. You must be 18 years old or older and a current foster parent to participate. If you are interested in participating in my survey, please copy and paste the following link into your browser (sometimes just clicking will not work):

https://acsurvey.qualtrics.com/SE/?SID=SV_1KQxFleAkLaLJFX

Thank you in advance for taking the time to complete my survey!

Leslie Nelson

1rnm9c@mail.missouri.edu

402-676-1988 


\section{APPENDIX B: CONSENT FORM}

Project Title: Exploring Foster Family Communication and Well-Being

Researcher: Leslie Nelson is a graduate student in the Department of Communication at the University of Missouri-Columbia.

Purpose: The purpose of this research project is to investigate how foster parents communicate with their foster children and how this impacts well-being.

Participants: To participate in this study, you must be: a) 18 years of age or older and b) currently fostering a child.

Time: $\quad$ In total, participation should take approximately 30 minutes.

Voluntary: Your participation is voluntary. You may quit at any time and you may refuse to answer any question on the survey.

Risk: $\quad$ There is minimal risk involved with the study. There is no more risk than you would experience in your daily interactions.

Benefits: $\quad$ Your input in this study can greatly help practitioners and researchers understand more about foster family communication and well-being.

Confidential: Your identity will not be revealed in the analysis, written documents, or verbal presentations of the data. The following steps will be taken to protect your identity and confidentiality:

1. Personal identifying information will be eliminated from the data and any reporting of the data

2. You can refuse to answer any question asked.

3. Data will be kept on a password-protected computer.

Contact: If you have questions, feel free to contact Leslie Nelson at 1rnm9c@mail.missouri.edu or 402-676-1988.

Questions: If you have questions about your rights as a participant, contact Campus IRB:

Office of Research 483 McReynolds Hall

Columbia, MO 65211

(573) 882-9585

Thank you for your participation! 
Leslie Nelson

Graduate Teaching Assistant

Department of Communication

University of Missouri-Columbia

By checking this box, I indicate that I meet the criteria for participation and I agree to participate in this survey:

A. I meet the criteria and agree to participate (note: if participants select this they will move on to the survey).

B. I do not meet the criteria and/or do NOT agree to participate (note: if participants select this the survey will close). 


\section{APPENDIX C: SURVEY INSTRUMENT}

Introduction: Foster families fill an important role in child welfare in society. However, researchers do not yet have a solid understanding of how foster families communicate. Because of this, I am interested in getting insight into your communication and experience as a foster parent.

First, please provide some demographical information about the child you will be referring to throughout the survey. If you are fostering more than one child currently, please refer to the child who has been in your home for the greatest amount of time:

What is the current age of your child (years)?

What is the sex of your child?
A. Male
B. Female

What is your child's Ethnic Background?
A. Asian American
B. Black/African American
C. Hawaiian or Pacific Islander
D. Hispanic/Latino
E. Native American
F. White/Caucasian
G. Other(s)

How old was your child when he/she entered your home? How long has your child been in your home?

How many homes was the child in before joining yours?

Thinking about your relationship with the child you selected, please respond to the following questions:

$\begin{array}{ccccccc}\begin{array}{c}\text { Strongly } \\ \text { Disagree }\end{array} & \text { Disagree } & \begin{array}{c}\text { Somewhat } \\ \text { Disagree }\end{array} & \begin{array}{c}\text { Neither Agree } \\ \text { nor Disagree }\end{array} & \begin{array}{c}\text { Somewhat } \\ \text { Agree }\end{array} & \text { Agree } & \begin{array}{c}\text { Strongly } \\ \text { Agree }\end{array} \\ \mathbf{1} & \mathbf{2} & \mathbf{3} & \mathbf{4} & \mathbf{5} & \mathbf{6} & \mathbf{7}\end{array}$

1. I am proud to be in the same family as my foster child.

2. My shared family membership with my foster child is not that important to me. (R)

3. Above all else, I think of my foster child as a member of my family.

4. My foster child is an important part of my family.

5. I feel as if my foster child and I are members of one family. 
6. I feel as if my foster child and I are members of separate groups. (R)

Thinking about your communication with the child you selected about his/her place in your family, please respond to the following questions:

\section{Strongly}

$\begin{array}{lllllllll}\text { Disagree } & 1 & 2 & 3 & 4 & 5 & 6 & 7 & \text { Strongly Agree }\end{array}$

1. I am a good listener when it comes to my child's thoughts and feelings about being placed in foster care.

2. It is difficult for me to understand foster care from my child's point of view.

3. I am very satisfied with how I talk with my child concerning his/her feelings about foster care placement.

4. If my child has problems or concerns related to foster care placement, he/she finds it easy to discuss them with me.

5. I am uncomfortable when my child asks questions about his/her birth parent(s).

6. My child can discuss his/her true thoughts and feelings about his/her foster care placement with me without feeling uncomfortable or embarrassed.

7. My child can discuss his/her true thoughts and feeling about his/her birth parent(s) with me without feeling uncomfortable or embarrassed.

8. When my child asks questions about his/her placement in foster care or about his/her birth parent(s), I give honest answers.

9. I understand what my child is feeling about his/her foster care placement without me having to ask.

10. My child feels very uncomfortable discussing his/her birth parent(s) with me.

11. It is easy for my child to express his/her thoughts and feelings about foster care placement with me.

12. If there is something my child needs to know about his/her placement in foster care, I am always there to try to answer questions.

13. I tell my child all I know about the reasons he/she is in foster care.

14. My child has thoughts and feelings about being in foster care or about his/her birth parent(s) that they feel they cannot share with me.

15. I make it easy for my child to ask questions about his/her foster care placement or about his/her birth parent(s).

Thinking about your general communication with the child you selected, please respond to the following questions:

$\begin{array}{lcccccc}\begin{array}{c}\text { Strongly } \\ \text { Disagree }\end{array} & \text { Disagree } & \begin{array}{c}\text { Somewhat } \\ \text { Disagree }\end{array} & \begin{array}{c}\text { Neither Agree } \\ \text { nor Disagree }\end{array} & \begin{array}{c}\text { Somewhat } \\ \text { Agree }\end{array} & \text { Agree } & \begin{array}{c}\text { Strongly } \\ \text { Agree }\end{array} \\ \mathbf{1} & \mathbf{2} & \mathbf{3} & \mathbf{4} & \mathbf{5} & \mathbf{6} & \mathbf{7}\end{array}$

1. In our family we often talk about topics like politics and religion where some persons disagree with others. 
2. I often say something like "Every member of the family should have some say in family decisions."

3. I often ask my child's opinion when the family is talking about something.

4. I encourage my child to challenge their ideas and beliefs.

5. I often say something like "You should always look at both sides of an issue."

6. My child usually tells me what s/he is thinking about things.

7. My child can tell me most anything.

8. In our family we often talk about our feelings and emotions.

9. My child and I have long relaxed conversations about nothing in particular.

10. I think my child really enjoys talking with me, even when we disagree.

11. I like to hear my child's opinions, even when s/he doesn't agree with me.

12. I encourage my child to express his/her feelings.

13. I tend to be very open about my emotions.

14. We often talk as a family about things we have done during the day.

15. In our family, we often talk about our plans and hopes for the future.

16. I often say things like "You'll know better when you grow up."

17. I often say things like "My ideas are right and you should not question them."

18. I often say things like "There are some things that just shouldn't be talked about."

19. I often say things like "You should give in on arguments rather than risk making people mad."

20. I often say things like, "A child should not argue with adults."

21 . When anything really important is involved, I expect my child to obey me without question.

22. In our home, the parents usually have the last word.

23. I feel that it is important for the parents to be the boss.

24. I sometimes become irritated with my child's views if they are different from mine.

25. If I don't approve of it, I don't want to know about it.

26 . When my child is at home, $\mathrm{s} / \mathrm{he}$ is expected to obey my rules.

With the child you selected in mind, please rate your child on the following items:

\section{Not at all}

$\begin{array}{lllll}\text { true } & 1 & 2 & 3 & \text { Absolutely true }\end{array}$

Age 4-10 (set survey so that if they report the child is $>4$ but $<10$ in the beginning, they get these items)

1.Considerate of other people's feelings

2.Restless, overactive, cannot stay still for long

3. Often complains of headaches, stomach-aches or sickness

4.Shares readily with other children, for example toys, treats, pencils

5.Often loses temper

6.Rather solitary, prefers to play alone

7.Generally well behaved, usually does what adults request 
8. Many worries or often seems worried

9.Helpful if someone is hurt, upset or feeling ill

10. Constantly fidgeting or squirming

11. Has at least one good friend

12. Often fights with other children or bullies them

13. Often unhappy, depressed or tearful

14. Generally liked by other children

15. Easily distracted, concentration wanders

16. Nervous or clingy in new situations, easily loses confidence

17. Kind to younger children

18. Often lies or cheats

19. Picked on or bullied by other children

20. Often offers to help others (parents, teachers, other children)

21. Thinks things out before acting

22. Steals from home, school or elsewhere

23. Gets along better with adults than with other children

24. Many fears, easily scared

25. Good attention span, sees work through to the end

Age 11-17 (set survey so that if they report the child is $>10$ and $<19$ in the beginning, they get these items)

1.Considerate of other people's feelings

2.Restless, overactive, cannot stay still for long

3. Often complains of headaches, stomach-aches or sickness

4. Shares readily with other youth, for example books, games, food

5.Often loses temper

6 . Would rather be alone than with other youth

7. Generally well behaved, usually does what adults request

8. Many worries or often seems worried

9.Helpful if someone is hurt, upset or feeling ill

10. Constantly fidgeting or squirming

11. Has at least one good friend

12. Often fights with other youth or bullies them

13. Often unhappy, depressed or tearful

14. Generally liked by other youth

15. Easily distracted, concentration wanders

16. Nervous in new situations, easily loses confidence

17. Kind to younger children

18. Often lies or cheats

19. Picked on or bullied by other youth

20. Often offers to help others (parents, teachers, children)

21 . Thinks things out before acting

22. Steals from home, school or elsewhere

23. Gets along better with adults than with other youth

24. Many fears, easily scared 
25. Good attention span, sees work through to the end

Please answer the following questions with the child you selected in mind:

\section{Not A Lot $\begin{array}{llllllll}1 & 2 & 3 & 4 & 5 & 6 & 7 & \text { A Lot }\end{array}$}

1. When you have leisure time how often do you choose to spend it with your child alone?

2. How often do you keep very personal information to yourself and do not share it with your child?

3. How often do you show your child affection?

4. How often do you confide very personal information to your child?

5 . How often are you able to understand your child's feelings?

6. How often do you feel close to your child?

7. How much do you like to spend time alone with your child?

8. How much do you feel like being encouraging and supportive to your child when he/she is unhappy?

9. How close do you feel to your child most of the time?

10. How important is it to you to listen to your child's very personal disclosures?

11. How satisfying is your relationship with your child?

12. How affectionate do you feel towards your child?

13. How important is it to you that your child understands your feelings?

14. How much damage is caused by a typical disagreement in your relationship with your child?

15. How important is it to you that your child be encouraging and supportive to you when you are unhappy?

16. How important is it to you that your child shows you affection?

17. How important is your relationship with your child in your life?

Lastly, please provide some demographical information about yourself:

What is your age?

Please indicate your sex:
A. Male
B. Female

What is your current relationship status?

A. Not currently in a romantic relationship 

B. Never married
C. Dating
D. Single, divorced or separated
E. Single, widowed
F. Long-term partnered/living together
G. Married

What is your Ethnic Background?
A. Asian American
B. Black/African American
C. Hawaiian or Pacific Islander
D. Hispanic/Latino
E. Native American
F. White/Caucasian
G. Other(s)

What is your highest level of education?
A. Some high school
B. Completed high school
C. Some college
D. Completed college
E. Some graduate school
F. Completed graduate school
G. Other:

Please indicate your total family income:
A. Under $\$ 20,000$
B. $\$ 20-30,000$
C. $\$ 31-40,000$
D. $\$ 41-50,000$
E. $\$ 51-60,000$
F. $\$ 61-70,000$
G. $\$ 71-80,000$
H. $\$ 81-90,00033$
I. $\$ 91-100,000$
J. over $\$ 100,000$

How long have you served as a foster parent in the foster care system (months)? How many children in the foster care system have you cared for in total? How many foster children do you currently have residing in your household? In total, how many children are currently residing in your household? 


\section{TABLE 1}

Descriptive statistics, reliability coefficients, and correlations

\begin{tabular}{|c|c|c|c|c|c|c|c|c|c|c|}
\hline Variables & 1 & 2 & 3 & 4 & 5 & 6 & 7 & 8 & 9 & 10 \\
\hline 1. Shared Family Identity & -- & & & & & & & & & \\
\hline 2. Communicative Openness & .10 & -- & & & & & & & & \\
\hline 3. Conformity Orientation & -.10 & $-.26 * *$ & -- & & & & & & & \\
\hline 4. Conversation Orientation & .17 & $.55^{* *}$ & $-.29 * *$ & -- & & & & & & \\
\hline 5. Child Strengths & .09 & $.23 * *$ & -.12 & $.33 * *$ & -- & & & & & \\
\hline 6. Child Difficulties & -.02 & -.08 & -.10 & $-.16^{* *}$ & $-.42 *$ & -- & & & & \\
\hline 7. Relational Closeness & $.45^{* *}$ & $.22 * *$ & -.12 & $.46^{* *}$ & $.34 * *$ & $-.23 * *$ & -- & & & \\
\hline 8. Foster Parent Sex & -.01 & .05 & $.24 * *$ & -.11 & -.05 & .09 & .07 & -- & & \\
\hline 9. Total Children Care For & .07 & $.20^{*}$ & -.02 & $.17 *$ & -.15 & -.02 & -.06 & .11 & -- & \\
\hline 10. Foster Child Age & .02 & $.20^{*}$ & .02 & .06 & -.01 & .14 & -.26 & $.71 *$ & $.28 * *$ & -- \\
\hline$M$ & 6.29 & 5.56 & 3.42 & 5.75 & 2.33 & 3.75 & 1.71 & .05 & 8.44 & 8.08 \\
\hline$S D$ & .91 & .71 & .85 & .66 & .51 & .46 & .38 & .22 & 7.09 & 4.93 \\
\hline$\alpha$ & .76 & .80 & .81 & .84 & .82 & .86 & .81 & -- & -- & -- \\
\hline
\end{tabular}

Note. Child strengths and difficulties scale endpoints were 1-3; relational closeness scale end points were 1-5; all other scale endpoints for measures were 1-7.

Note. Females $=0$ and males $=1$.

$* p<.05 . * * p<.01$. 